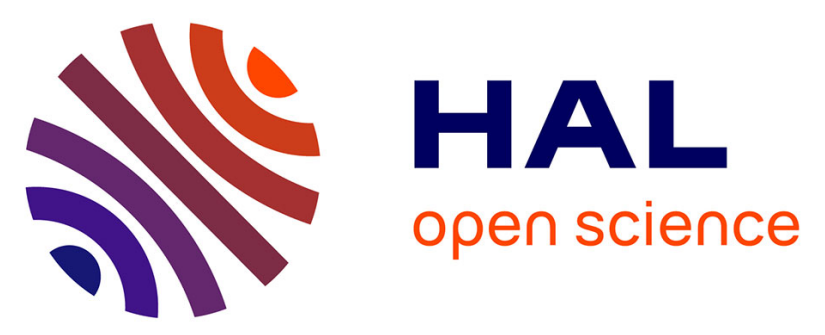

\title{
Recent advances in metalloporphyrin-based catalyst design towards carbon dioxide reduction: from bio-inspired second coordination sphere modifications to hierarchical architectures
}

Philipp Gotico, Zakaria Halime, Ally Aukauloo

\section{To cite this version:}

Philipp Gotico, Zakaria Halime, Ally Aukauloo. Recent advances in metalloporphyrin-based catalyst design towards carbon dioxide reduction: from bio-inspired second coordination sphere modifications to hierarchical architectures. Dalton Transactions, 2020, 10.1039/c9dt04709c . hal-02481325

\section{HAL Id: hal-02481325 \\ https://hal.science/hal-02481325}

Submitted on 10 Nov 2020

HAL is a multi-disciplinary open access archive for the deposit and dissemination of scientific research documents, whether they are published or not. The documents may come from teaching and research institutions in France or abroad, or from public or private research centers.
L'archive ouverte pluridisciplinaire HAL, est destinée au dépôt et à la diffusion de documents scientifiques de niveau recherche, publiés ou non, émanant des établissements d'enseignement et de recherche français ou étrangers, des laboratoires publics ou privés. 
Received 00th

January 20xx,

\title{
Recent Advancements in Metalloporphyrin-Based Catalyst Design Towards Carbon Dioxide Reduction: From Bio-inspired Second Coordination Sphere Modifications to Hierarchical Architectures
}

\author{
Philipp Gotico, ${ }^{a}$ Zakaria Halime, ${ }^{* b}$ and Ally Aukauloo*a,b
}

Accepted 00th January 20xx DOI: $10.1039 / \times 0 \times x 00000 x$

\begin{abstract}
Research in the development of new molecular catalysts for the selective transformation of $\mathrm{CO}_{2}$ to reduced forms of carbon is gathering an enormous effort from chemists. Molecular catalyst design hinges on the elaboration of ligand scaffolds to manipulate the electronic and structural properties for the fine tuning of the reactivity pattern. A cornucopia of ligand sets has been designed along this line and still increasing. In this quest, the porphyrin molecular platform has been under intensive focus for the unmatched catalytic properties of the metalloporphyrins. Advances in this particular field have been blooming during these last years where both electronic and structural aspects in the second coordination spheres have been adressed to shift the overpotential, and improve the catalytic rates and product selectivity. Metalloporphyrins have also attracted much attention in the elaboration of hybrid materials for heterogeneous catalysis. Here too, the promising activities put metalloprphyrins derivatives as serious candidates for technological implementation. This review collects the recent advances around the chemistry of metalloporphyrins in the reduction of $\mathrm{CO}_{2}$.
\end{abstract}

\section{Introduction}

Intense global efforts are put in place to address climate change which is already affecting and will persist to worsen the state of living. ${ }^{1}$ Carbon dioxide $\left(\mathrm{CO}_{2}\right)$ capture, conversion, storage, and utilization technologies have been proposed with an emphasis on the role of the latter in driving a global scale implementation of a low-carbon and energy-efficient chemical and fuel production. $^{2,3}$ In light of this call, the field of artificial photosynthesis is an ideal resource-efficient solution, trying to mimic how plants use sustainable sources of sunlight, $\mathrm{CO}_{2}$ and water to drive the production of energy-rich carbohydrates. As such, promising research efforts have been intensified in reducing $\mathrm{CO}_{2}$ into similar energy-rich fuels and chemical feedstocks through electro- and photo-catalytic routes. This strategy results in a closed carbon-recycling loop, able to transform waste $\mathrm{CO}_{2}$ emissions into usable products. Integrating this approach with a renewable solar energy source then results in an ideal net negative carbon footprint, and simultaneously address the critical concern on the intermittency of the solar energy supply.

The first basic question we need to raise is how do we transform $\mathrm{CO}_{2}$ ? A look on the molecular orbital diagram of $\mathrm{CO}_{2}$ shows a fully filled bonding and nonbonding $\sigma$ and $\pi$ orbitals,

a. Institut de Biologie Intégrative de la Cellule (I2BC), Institut des Sciences du Vivant Frédéric-Joliot, CEA Saclay, Gif-sur-Yvette 91191, France.

E-mail:ally.aukauloo@u-psud.fr

b. Institut de Chimie Moléculaire et des Matériaux d'Orsay (UMR CNRS 8182),

Université Paris-Sud, Orsay 91405, France. rendering a highly stable molecule (Figure 1a). The initial step to activate and transform the molecule involves an electron transfer (i.e. a reduction process) that occupies the $\sigma^{*}$ antibonding lowest unoccupied molecular orbital (LUMO). This causes the increase in the $\mathrm{C}$-O distance, manifested in the bending of the initially linear molecule. ${ }^{4}$ This bent molecule can then more easily interact with electrophiles and nucleophiles through its charge-localized frontier orbitals.

This one-electron reduction of $\mathrm{CO}_{2}$ to $\mathrm{CO}_{2}{ }^{\bullet-}$ however, is a highly endergonic reaction occurring at a reduction potential of $\mathrm{E}^{\circ}=-1.90 \mathrm{~V}$ vs. NHE (Figure 1b). This is due to a large reorganizational barrier between the linear molecule and bent radical anion. However, performing multi-proton and multielectron steps are more favourable than single electron reduction because they can lead to thermodynamically more
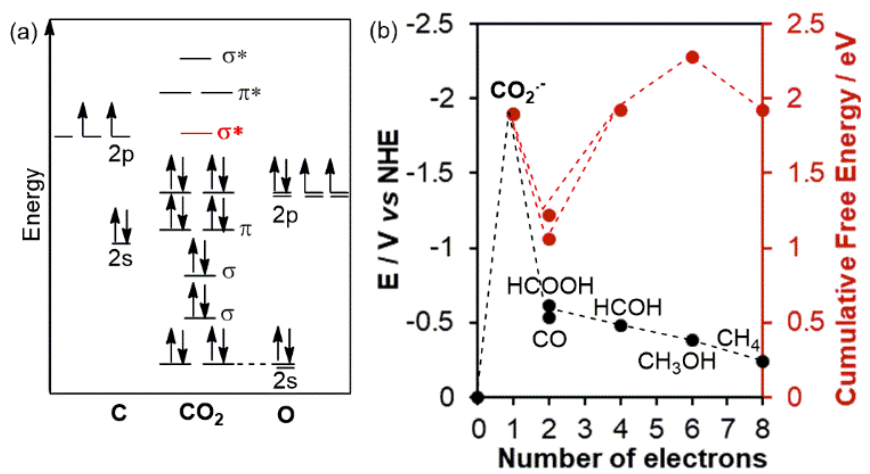

Figure 1. (a) Molecular orbital diagram of a carbon dioxide molecule and (b) the thermodynamic requirements for its activation and succeeding reduction processes. 
stable molecules like carbon monoxide (CO), formic acid $(\mathrm{HCOOH})$, formaldehyde $(\mathrm{HCOH})$, methanol $\left(\mathrm{CH}_{3} \mathrm{OH}\right)$, and methane $\left(\mathrm{CH}_{4}\right)$ as products. This thermodynamic ease comes however with a kinetic cost of bringing together all the protons and electrons in appropriate pathways to result in the desired reaction. As such, to transform $\mathrm{CO}_{2}$ by overcoming the thermodynamic and kinetic barriers of its reduction, catalysts are needed to stabilize intermediate transition states.

In addition, energy is still needed to be introduced into the reaction mixture to drive the reduction reactions because of the intrinsic overpotential of catalytic systems. The overpotential corresponds to the energetic barrier to overcome before any redox electrochemical reaction can take place. This can be ideally supplied by renewable solar energy resource, standing as one of the pillars of artificial photosynthesis. Two approaches are envisioned, as shown in Figure 2. One is a photo-catalytic approach consisting of a photosensitizer (PS) capable of absorbing light and creating charge separated states (electron and hole). The holes are replenished by an electron donor (ED), and the electrons are used to activate a reduction catalyst ( $\mathrm{Cat}_{\text {red }}$ ) for $\mathrm{CO}_{2}$ reduction. On the other hand, an electrocatalytic system takes leverage of advancements in photovoltaics, able to convert light energy to electricity and deliver the necessary electrons to Cat $_{\text {red }}$ in an electrolyser-type configuration.

Central to these approaches is the design of catalysts that can efficiently and selectively reduce $\mathrm{CO}_{2}$. Most of the $\mathrm{CO}_{2}$ reduction catalysts contain a central transition metal atom that is supported by a coordinated ligand framework. The metal centre usually acts as the point of binding for the $\mathrm{CO}_{2}$ substrate and it is typically responsible for transferring the electrons to the substrate. Equally important is the ligand framework which supports and stabilizes the reduced metal and/or can also be the locus for accumulation of charges in its framework henceforth allowing the storage of multiple reducing

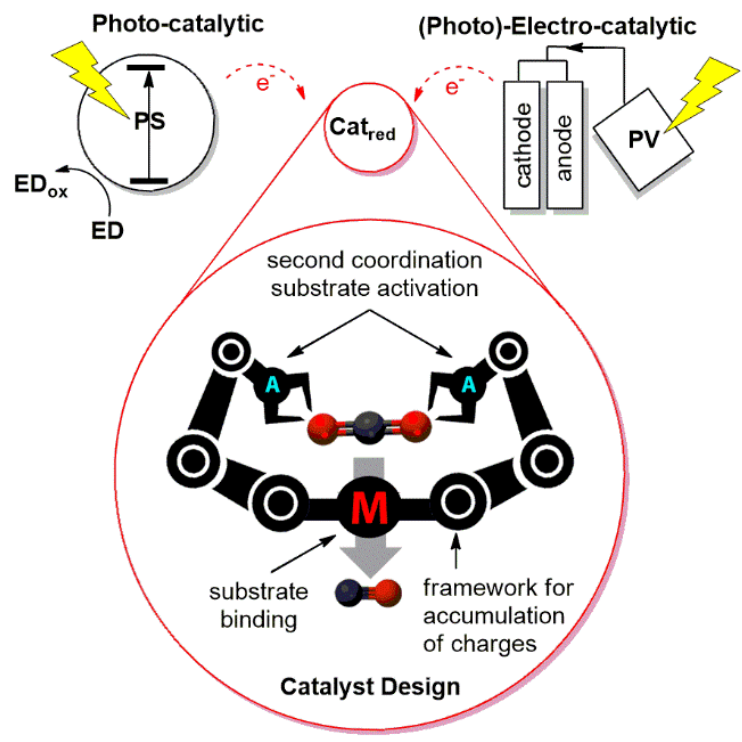

Figure 2. Simplified diagrams for the photo- and (photo)-electro-catalytic approaches in reducing $\mathrm{CO}_{2}$ with an overarching theme of catalyst design. (ED = electron donor, $\mathrm{PS}=$

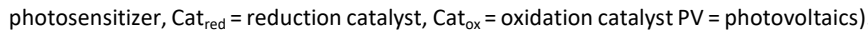

equivalents across the molecule. They are generally categorized into two grand families; the innocent and non-innocent ligands. Aza-macrocycles such as cyclam, phosphines, and sulphurcontaining ligands constitute the former ligand sets while $\pi$ containing systems such as porphyrins and similar macrocyclic ligands (phthalocyanines or azaporphyrazines), and polypyridyl ligands (e.g. bipyridines, phenanthrolines, terpyridines, quaterpyridines, etc.) constitute the latter. There is recently a vast literature ${ }^{5-13}$ reviewing the different combination of transition metals and ligand frameworks employed to reduce carbon dioxide.

This review article will present the recent advancements in catalyst design for metalloporphyrin-based $\mathrm{CO}_{2}$ reduction catalysts for several reasons: (i) they are biologically known to store multiple charges ${ }^{14}$ that would be beneficial in addressing the multi-electron steps involved in $\mathrm{CO}_{2}$ reduction processes, (ii) they have been extensively studied because of ease and variety of peripheral ligand modifications without significantly modifying the first coordination sphere functionalities, and (iii) they are more fairly compared within their family because of well-established benchmarking schemes. ${ }^{15-18}$ Current strategies in homogenous catalysis using bio-inspired second coordination sphere modifications and further developments towards hierarchical architectures in heterogeneous catalysis will be comprehensively examined to provide general guidelines and future opportunities for improving the efficiency and selectivity of $\mathrm{CO}_{2}$ reducing catalysts.

\section{Homogenous $\mathrm{CO}_{2}$ Reduction}

\subsection{Mechanism of $\mathrm{CO}_{2}$-to-CO Electrocatalytic Reduction by Iron- Tetraphenylporphyrins}

Investigations on the use of metalloporphyrins for the reduction of $\mathrm{CO}_{2}$ go back in the early $80^{\prime} \mathrm{s}^{19}$ and it was the pioneering electrochemical and mechanistic studies by Savéant and coll. on iron (III) tetraphenylporphyrin (FeTPP, catalyst 1) that boosted further developments. ${ }^{20}$ The efficient, selective, and wellcharacterized electrochemical response of this molecular catalyst, as well as the variety of opportunities for ligand modifications and catalytic improvements paved the way to the seminal use of such platform for researches in the field of $\mathrm{CO}_{2}$ reduction catalysis.

In a general proposed mechanism, 1 undergoes three reversible reductions as evidenced by three reversible peaks in its cyclic voltammogram (Figure 3a). These corresponds to the formal reductions from $\mathrm{Fe}^{\mathrm{III}}$ to $\mathrm{Fe}^{\mathrm{Il}}$ to $\mathrm{Fe}^{\mathrm{l}}$ and finally to the $\mathrm{Fe}^{\mathrm{O}}$ active form. Recent reports from the group of Neese using a comprehensive set of spectroscopic techniques and computational studies suggest that the last two electrons reside in the $\pi^{*}$ orbitals of the porphyrin ligand. ${ }^{21,22}$ As such, the last two redox couples can be formulated as [Fe"TPP]/[Fe" "TPP* $\left.^{*}\right]^{-}$ and $\left[\mathrm{Fe}^{\prime \prime}\left(\mathrm{TPP}^{\bullet}\right)\right]^{-} /\left[\mathrm{Fe}^{\prime \prime}(\mathrm{TPP} \cdot \bullet)\right]^{2-}$. Since these electrons are delocalized in the conjugated macrocycle, the corresponding electron transfer will involve marginal geometric distortions of the ligand, and hence a lower reorganizational energy. 
(a)
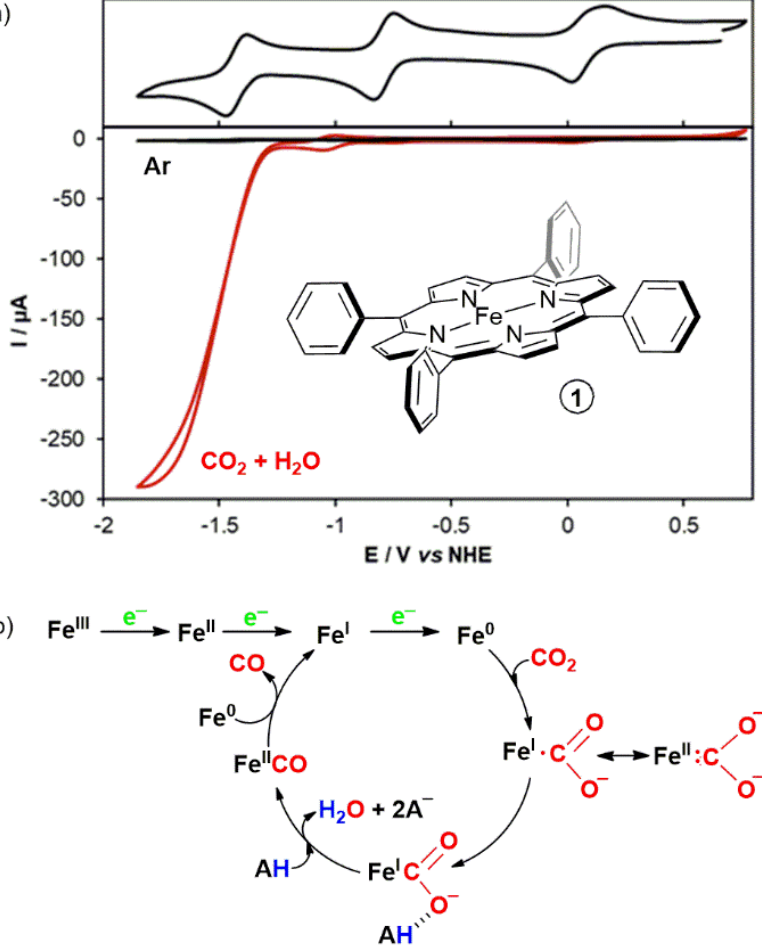

Figure 3. (a) Cyclic voltammetry of iron tetraphenylporphyrin (FeTPP, 1) in dimethylformamide containing $0.1 \mathrm{M} \mathrm{TBAPF}_{6}$ under argon (black) and upon $\mathrm{CO}_{2}$ saturation and addition of $5.5 \mathrm{M} \mathrm{H}_{2} \mathrm{O}$ (red), with (b) the proposed mechanism.

The formal $\mathrm{Fe}^{0}$ species reacts with the $\mathrm{CO}_{2}$ substrate producing two mesomeric forms: $\left[\mathrm{Fe}^{\prime}\left(\mathrm{CO}_{2}^{*}\right)\right]^{2-}$ and $\left[\mathrm{Fe}^{\prime \prime}\left(\mathrm{CO}_{2}{ }^{\bullet}\right)\right]^{2-}$ as shown in Figure $3 \mathrm{~b}$. Though there are no reported experimental evidence of the $\mathrm{CO}_{2}$ adduct yet for $1,{ }^{23-25}$ it was proposed that the reaction goes through the $\mathrm{Fe}^{\mathrm{l}}$ dissymmetrical adduct, stabilized by a hydrogen bond donor, rather than the $\mathrm{Fe}^{\text {Il }}$ symmetrical adduct. ${ }^{26}$ It is then followed by a concerted process of protonation and intramolecular electron transfer, breaking one of the $\mathrm{C}-\mathrm{O}$ bond to form a $\mathrm{Fe}^{\mathrm{Il}}-\mathrm{CO}$ intermediate, as proposed by the group of Savéant based on cyclic voltammetry and isotopic $H / D$ studies. This underlines the importance of Lewis acids (e.g. $\left.\mathrm{Mg}^{2+}\right)^{27}$ and $\mathrm{Br} \varnothing$ nsted acids (e.g. $\left.\mathrm{H}_{2} \mathrm{O}, \mathrm{PhOH}, \mathrm{CF}_{3} \mathrm{CH}_{2} \mathrm{CO}_{2} \mathrm{H}\right)^{28,29}$ in improving the efficiency and lifetime of the catalysis as initially reported. $\mathrm{CO}$ is released after homogeneous one-electron reduction by another $\mathrm{Fe}^{0}$ species in a comproportionation process, closing the catalytic cycle. ${ }^{18}$

The group of Dey have successfully characterized two intermediates involved in the proposed catalytic cycle using a modified iron porphyrin bearing distal hydrogen bonding pockets (catalyst 24, Figure 8). ${ }^{25}$ Resonance Raman spectra (recorded at $-95^{\circ} \mathrm{C}$ ) and DFT calculations suggested an initial symmetrical $\mathrm{Fe}^{\mathrm{II}}-\mathrm{CO}_{2}{ }^{2-}$ intermediate, a resonance form of the initially proposed dissymmetrical intermediate. This intermediate is similarly followed by a protonation step to form $\mathrm{Fe}^{\mathrm{Il}} \mathrm{- \textrm {COOH }}$ intermediate. The trapped intermediates are specific to the conditions employed in the study (solvent, proton source and temperature) but they are generally in line with the proposed mechanism for iron porphyrins.
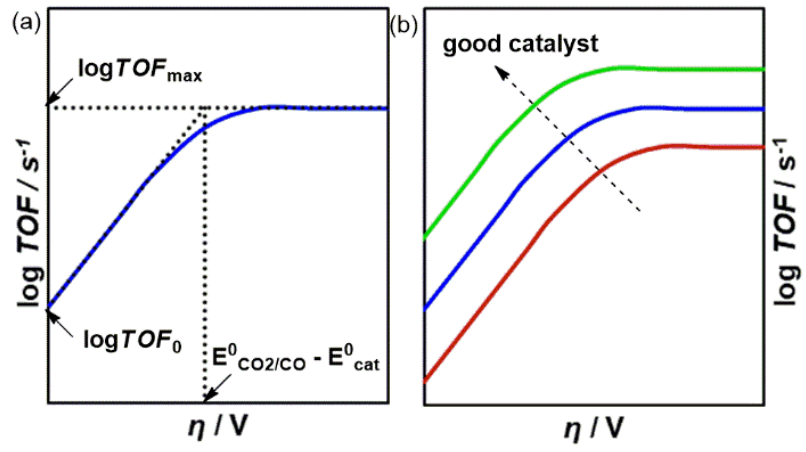

Figure 4. (a) Catalytic Tafel plot established based on catalytic parameters estimated by foot-of-the-wave (FOW) analysis with (b) features of good catalysis.

\subsection{Benchmarking of Catalyst Performance}

The group of Savéant has also developed a benchmarking strategy to easily and fairly compare the electrocatalytic $\mathrm{CO}_{2}$ reduction performance using foot-of-the-wave (FOW) analysis of the cyclic voltammogram of the catalytic system. ${ }^{15,17,26,30}$ This quick evaluation technique gives an indication as to how fast a catalytic system can be driven in terms of the catalytic rate constant $\left(k_{c a t}\right)$ and turnover frequency (TOF) preventing any contributions from side phenomena such as substrate consumption, catalyst deactivation, and/or product inhibition. The FOW analysis has been successfully applied to a variety of modified iron-porphyrin catalysts with estimations close to those obtained from bulk electrolysis experiments. ${ }^{31,32}$

The analysis is based on the linear correlation between $i / i_{\mathrm{p}}{ }^{0}$ and $1 /\left\{1+\exp \left[F / R T\left(E-E_{\text {cat }}^{0}\right)\right]\right\}$ where $i$ is the catalytic current in the presence of $\mathrm{CO}_{2}, i_{\mathrm{p}}{ }^{0}$ is the peak current in the absence of $\mathrm{CO}_{2}, F$ is the Faraday constant, $R$ is the gas constant, $T$ is the absolute temperature, $E$ is the applied potential, and $E_{\text {cat }}^{0}$ is the standard potential of the reversible reduction peak of the catalyst's active form (i.e. Fel/0 couple).

$$
\frac{i}{i_{p}^{0}}=\frac{2.24 \sqrt{\frac{R T}{F v} k_{c a t} C_{c a t}^{0}}}{1+\exp \left[\frac{F}{R T}\left(E-E_{c a t}^{0}\right)\right]}
$$

Plotting $i / i_{\mathrm{p}}{ }^{0}$ vs. $1 /\left\{1+\exp \left[F / R T\left(E-E_{\text {cat }}^{0}\right)\right]\right\}$ gives rise to a straight line with a slope $=2.24(R T / F v)^{0.5}\left(k_{\text {cat }} C^{0}{ }_{\text {cat }}\right)^{0.5}$ where $v$ is the scan rate in V.s $s^{-1}$ and $C^{0}$ cat is the initial concentration of the substrate (i.e. $\mathrm{CO}_{2}$ ). From this slope, $k_{\text {cat }}$ can be determined, and consequently a catalytic Tafel plot can be traced by plotting log TOF vs. overpotential, $\eta$ (i.e. $\eta=E^{O} \mathrm{CO}_{/} \mathrm{CO}-E$, where $E^{0} \mathrm{CO} / \mathrm{CO}$ is the thermodynamic potential for the $\mathrm{CO}_{2}$ reduction process involved and $E$ is the applied potential):

$$
\begin{gathered}
T O F_{\text {max }}=k_{c a t} C_{c a t}^{0} \\
T O F=\frac{T O F_{\text {max }}}{1+\exp \left[\frac{F}{R T}\left(E_{c a t}^{0}-E_{\mathrm{CO}_{2} / \mathrm{CO}}^{0}-\eta\right)\right]}
\end{gathered}
$$

at $\eta=0, \log T O F_{0}=\left[\log T O F_{\text {max }}-\frac{F}{R T \ln 10}\left(E_{\mathrm{CO}_{2} / \mathrm{CO}}^{0}-E_{\text {cat }}^{0}\right)\right]$

$$
\log T O F=\left(\frac{F}{R T \ln 10}\right) \eta+\log T O F_{0}
$$


The plot of log TOF vs. $\eta$ (Figure 4a) shows two asymptotes: at large overpotentials, log TOF $\rightarrow \log T O F_{\max }$, and at low overpotentials, log TOF $\rightarrow \log T_{O} F_{0}+\eta^{*}(F / R T \ln 10)$, where TOF is an intrinsic descriptor of the catalyst operating at zero overpotential. As such, just knowing $E_{\text {cat }}^{0}$ and $T O F_{0}$ or $T O F_{\max }$ of the system, one can retrace a catalytic Tafel plot and evaluate the catalytic performance of the catalyst. With the goal of improving the catalytic rate (higher $T O F_{0}$ or $T O F_{\max }$ ) and lowering the overpotential of the system, a good catalyst would be envisioned to have a catalytic Tafel plot shifted upwards to the left, as shown in Figure 4b.

For example, the classical strategy of lowering the overpotential of a catalyst is through the modification of the porphyrin ligand by incorporating substituents that can induce through-structure electronic effects. For example, the introduction of electron withdrawing groups such as fluorine atoms is expected to lower the overpotential because it lowers the electron density near the metal active site. Thus, it is easier to inject an electron into the catalyst, shifting the reduction potential anodically which results in a lower overpotential. This can be observed for the addition of increasing number of fluorine atoms from 5 to 20 (catalysts $2,3, \mathbf{4}, \mathbf{5}$ ), resulting in a lower overpotential compared to the nonfunctionalized catalyst $\mathbf{1}$ (leftward shift of the catalytic Tafel plot in Figure 5a). ${ }^{33-36}$ This comes however, with a decrease in the catalytic activity (downward shift of the Tafel plot) due to the decrease of the nucleophilicity of the active form of the catalyst and its ability to activate the $\mathrm{CO}_{2}$ substrate.

An easier comparison of the overlapping catalytic Tafel plots of Figure $5 \mathrm{a}$ can be made by plotting the log TOF $F_{\max }$ of the catalyst and the overpotential related to the catalytic redox
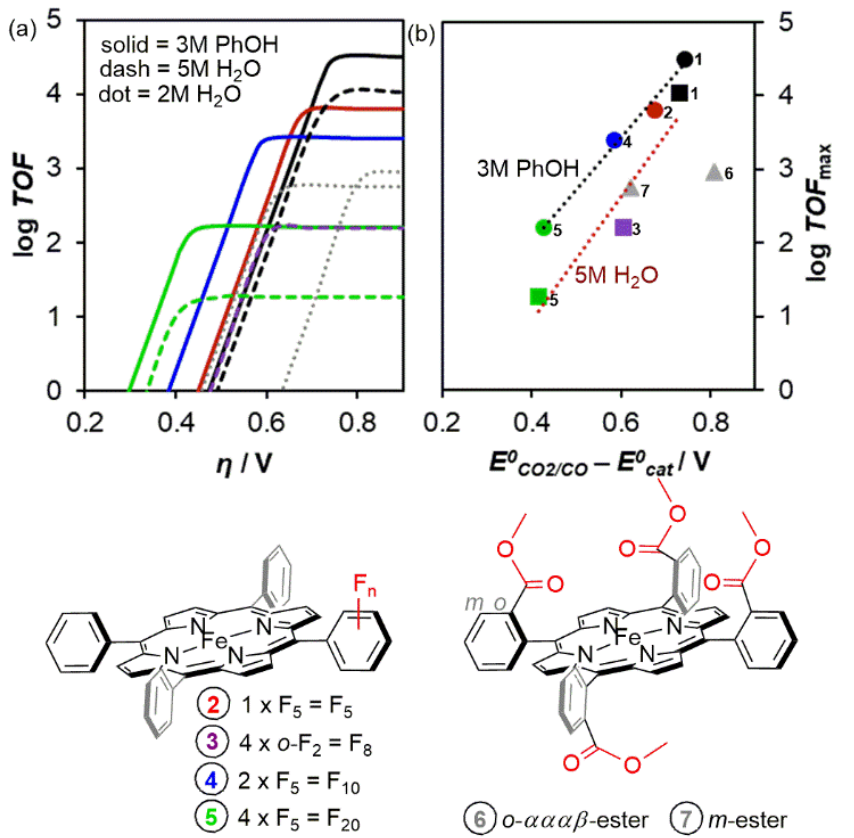

(6) $o$ - $\alpha \alpha \alpha \beta$-ester (7) $m$-ester

Figure 5. (a) Catalytic Tafel plots of iron porphyrins modified with fluorine or ester groups with structures shown at the bottom. (b) Correlation of $T O F_{\max }$ with the catalytic potential $E_{\text {cat }}^{0}$ showing through-structure substituent effects. Conditions: DMF with $3 \mathrm{M}$ $\mathrm{PhOH}$ (circle) or $5 \mathrm{M} \mathrm{H}_{2} \mathrm{O}$ (square) or $2 \mathrm{M} \mathrm{H}_{2} \mathrm{O}$ (triangle). Color legends between (a) and (b) are related to the indicated structures. couple $\left(\eta^{\prime}=E^{O}{ }_{C O 2 / C O}-E_{c a t}^{O}\right)$, as shown in Figure $5 \mathrm{~b}$. This data point is simply the point of intersection between the two asymptotes of the catalytic Tafel plot. Even though this data point lies beyond the Tafel plot, the ease of identification of such correlation point, which still includes characteristic catalytic information, will become useful especially when comparing numerous catalysts. As shown in Figure $5 \mathrm{~b}$, the through-structure electronic substituent effect of fluorinated groups lies within a straight correlation line, similar to a Hammett-type linear free-energy relationship. ${ }^{18}$ This shows that favouring one catalytic parameter (i.e. lowering the overpotential) disfavours another one (i.e. TOF). In addition, careful positioning of through-structure substitutions should be considered, as the addition of ester groups in the meta- or ortho-positions of the meso aryls in catalysts $\mathbf{6}$ and $\mathbf{7}$ can easily shift the overpotential, without significant differences in the catalytic rate. ${ }^{37}$ The greater challenge in synthetic catalyst design is then to escape these linear correlations and succeed in lowering the overpotential of the catalytic reaction while maintaining high TOF.

\subsection{Bio-inspired Catalyst Modifications}

One way of addressing the challenge of catalyst design is to take inspiration from natural systems which evolved over millions of years to perform efficient redox reactions at lower energetic costs. In nature, there are six pathways known to fix carbon dioxide as organic material for biomass. ${ }^{4}$ The dominant process is the reductive pentose phosphate (Calvin-Benson-Bassham) cycle which involves the ribulose bisphosphate carboxylase/oxygenase (RuBisCO) catalysing the reaction of $\mathrm{CO}_{2}$ with a five-carbon sugar 1,5-ribulose bisphosphate to form two molecules of 3-phosphoglycerate (a precursor for a series of interconversions to form the six-carbon sugar fructose-1,6bisphosphate). ${ }^{38}$ The other five pathways all involve net reactions of producing acetyl-CoA from $\mathrm{CO}_{2}$ for anabolic (biosynthesis) and catabolic (energy) purposes: reductive acetyl-CoA pathway, reductive citric acid cycle, dicarboxylate / 4-hydroxybutyrate cycle, 3-hydroxypropionate / 4hydroxybutyrate cycle, and 3-hydroxypropionate bi-cycle. ${ }^{39}$

Though the thermodynamically favourable multi-electron reductions of $\mathrm{CO}_{2}$ are very important reactions, they are surprisingly not observed in natural systems, which instead use discrete two-electron reduction steps. For example, the WoodLjungdahl pathway for autotrophic growth and acetate synthesis involves initial two-electron reduction steps: the $\mathrm{CO}$ dehydrogenase ( $\mathrm{CODH}$ )-catalysed reduction of $\mathrm{CO}_{2}$ to $\mathrm{CO}$ and the formate dehydrogenase (FDH)-catalysed reduction of $\mathrm{CO}_{2}$ to formate. Similar discrete two-electron steps are involved in the eight-electron reduction reactions observed for methanogenic archaea catalysing reduction of $\mathrm{CO}_{2}$ to methane and for acetogenic bacteria catalysing reduction of $\mathrm{CO}_{2}$ to acetic acid. Reasons for this strategy include (i) the versatility of these two-electron reduced intermediates to branch off into various pathways for the synthesis of cellular metabolites, and (ii) the final products (e. g. methane, acetic acid) are usually just byproducts in the overall energy conservation scheme. ${ }^{40}$ As such, 

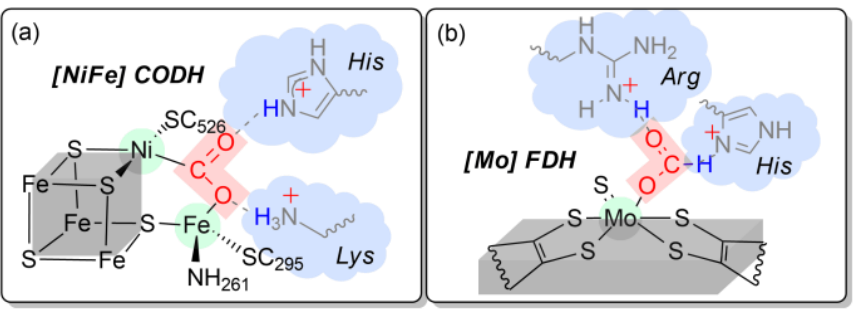

Figure 6. $\mathrm{CO}_{2}$-adduct intermediates found in the active site of (a) [NiFe]-centred carbon monoxide dehydrogenase (CODH) and (b) [Mo]-centred formate dehydrogenase (FDH) showing some common strategies for bio-inspired catalyst design.

fundamental learnings from the biological two-electron reduction of $\mathrm{CO}_{2}$ to $\mathrm{CO}$ and formate would be particularly interesting in designing synthetic $\mathrm{CO}_{2}$ reduction catalysts.

The active sites of these enzymes ${ }^{4,41-45}$ are shown in Figure 6 and they seemingly comprise similar features that could be starting points for bio-inspired design. First, they consist of sulphur-rich ligand structures $\left(\mathrm{Fe}_{3} \mathrm{~S}_{4}\right.$ cluster and pterin-like cofactors) that can store and supply electrons. Second, they employ a substrate-activating environment either by bifunctional Lewis acid-base pair or second coordination sphere activation by nearby amino acid residues. Third, they promote good $\mathrm{CO}_{2}$ binding in meticulously pre-arranged active sites with minimal changes in the geometry, resulting in low reorganizational energies (and consequently lower overpotentials). Lastly, they take leverage of the flexibility of their aqueous environment to manage the proton supply, and promote proton-coupled electron transfer steps, significantly lowering the thermodynamic requirement of the reduction reactions.

Most bio-inspired approaches take into consideration these features by implementing a second coordination sphere effect for known $\mathrm{CO}_{2}$ reduction catalysts. Second coordination sphere relates to the distal structure of the catalyst beyond the primary coordination sphere of the ligand platform with the metal centre that may influence metal-bound intermediates and may or may not affect the electronic structure of the catalyst. Strategies relying on such effect have initially been extensively implemented in various synthetic catalysts for the reduction of dioxygen and reduction of protons, mimicking features observed in natural systems. Recently, this has been applied to the development of $\mathrm{CO}_{2}$ reduction catalysts ${ }^{18,46-48}$ and specific approaches can be generally categorized in the following: establishing local proton sources, tethering hydrogen bond relays, leveraging on cationic groups, and employing bimetallic structures.

\subsubsection{Local Proton Source}

The observation that addition of weak Brønsted acids ${ }^{26}$ enhances the catalytic reduction of $\mathrm{CO}_{2}$ already hinted the possibility of placing local acid proton sources in the periphery of the catalyst. This has been initially reported by the group of Savéant by placing eight pendant hydroxyl groups in FeTPP as shown in catalyst 9 (Figure 7). ${ }^{31}$ The introduction of these pendant proton donors resulted in enhanced $\mathrm{CO}_{2}$-to- $\mathrm{CO}$ catalytic activity $\left(\log T O F_{\max }=5.97\right)$ at lower overpotential $\left(\eta^{\prime}=\right.$
$0.64 \mathrm{~V}$ ) in DMF with $2 \mathrm{M} \mathrm{H}_{2} \mathrm{O}$ (square markers in Figure 7) compared with nonfunctionalized catalyst $\mathbf{1}$ in the same condition $\left(\log T O F_{\max }=2.75, \eta^{\prime}=0.74 \mathrm{~V}\right)$. The study also showed that replacing hydroxyl $(-\mathrm{OH})$ groups by methoxy $\left(-\mathrm{OCH}_{3}\right)$ groups (catalyst 11) results in a poorer activity $\left(\log T O F_{\max }=2.7\right)$ at a much larger overpotential $\left(\eta^{\prime}=1.00 \mathrm{~V}\right) .{ }^{16}$ In the presence of only one pendant hydroxyl group in catalyst $\mathbf{8}$, the catalytic activity was significantly decreased $\left(\log T O F_{\max }=2.1, \eta^{\prime}=0.91 \mathrm{~V}\right),{ }^{49}$ highlighting the crucial role of high local proton concentration in a push-pull (electron-proton) mechanism towards the metal carboxylate intermediate. ${ }^{26}$

The choice of the external proton source and the solvent is a critical factor for the activity of such type of catalyst. When using $3 \mathrm{M} \mathrm{PhOH}$ (circular markers in Figure 7) instead of $\mathrm{H}_{2} \mathrm{O}$ in DMF, the same catalyst 9 does not show significant improvements $\left(\log\right.$ TOF $\left._{\max }=3.8, \eta^{\prime}=0.66 \mathrm{~V}\right)$ compared to catalyst $1\left(\log T O F_{\max }=4.5, \eta^{\prime}=0.74 \mathrm{~V}\right) .{ }^{32}$ Introducing 10 fluorine atoms as electron withdrawing groups in catalyst 10 slightly lowered the overpotential $\left(\eta^{\prime}=0.59 \mathrm{~V}\right)$ but the activity $\left(\log T O F_{\max }=4.0\right)$ is still lower than that of catalyst $1 .{ }^{32}$ This implies that the pendant phenolic groups in catalysts $\mathbf{9}$ and $\mathbf{1 0}$ compete with the bulk concentrations of phenol in stabilizing the metal carboxylate intermediate. In presence of $\mathrm{H}_{2} \mathrm{O}$ as external Brønsted acid, however, catalyst 9 exerts a more local acidic environment directly interacting with the metal carboxylate intermediate. It is also noteworthy to point out that when switching the solvent from the commonly used dimethylformamide (DMF) to acetonitrile (ACN), a significant improvement in the catalytic activity was observed for catalyst $8\left(\log T O F_{\max }=3.7\right)$ at lower overpotential $\left(\eta^{\prime}=0.78 \mathrm{~V}\right)$ in comparison with the same catalyst in DMF. ${ }^{49}$ It was pointed out by the group of Warren that the unexpected solvent effect was due to the strong $\mathrm{H}$-bond acceptor ability of DMF compared to

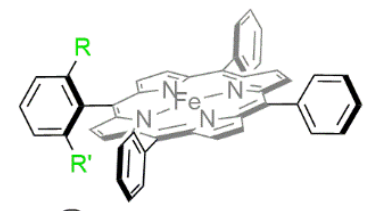

(8) $1 \times\left(\mathrm{R}=\mathrm{OH}, \mathrm{R}^{\prime}=\mathrm{H}\right)$

(9) $4 \times\left(\mathrm{R}=\mathrm{R}^{\prime}=\mathrm{OH}\right)$

(10) $2 \times\left(\mathrm{R}=\mathrm{R}^{\prime}=\mathrm{OH}\right) ; 2 \times \mathrm{F}_{5}$

(11) $4 \times\left(\mathrm{R}=\mathrm{R}^{\prime}=\mathrm{OCH}_{3}\right)$

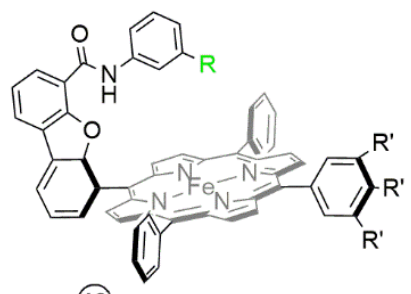

(12.) $\mathrm{R}=\mathrm{OH} ; 3 \times\left(\mathrm{R}^{\prime}=\mathrm{OCH}_{3}\right)$

(13) $\mathrm{R}=\mathrm{SO}_{3} \mathrm{H} ; 3 \times\left(\mathrm{R}^{\prime}=\mathrm{OCH}_{3}\right)$
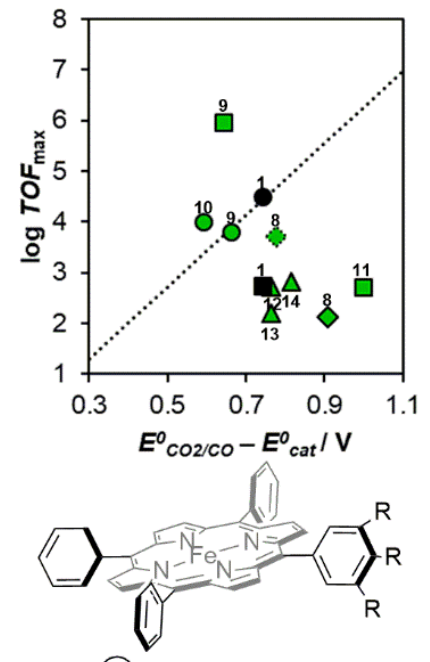

(14) $4 \times\left(\mathrm{R}=\mathrm{OCH}_{3}\right)$

Figure 7. Effect of functional groups acting as local proton source in the second coordination sphere of modified iron porphyrins. Conditions: DMF with $3 \mathrm{M} \mathrm{PhOH}$ (circle) or $0.04 \mathrm{M} \mathrm{PhOH}$ (triangle) or $2 \mathrm{M} \mathrm{H}_{2} \mathrm{O}$ (square) or $1 \mathrm{M} \mathrm{H}_{2} \mathrm{O}$ (diamond); $\mathrm{ACN}$ with $1 \mathrm{M} \mathrm{H}_{2} \mathrm{O}$ (dotted diamond). Through-structure relation from Figure 5 and performance of nonfunctionalized catalyst $\mathbf{1}$ are shown for relative comparison. 
ACN, disrupting the pre-established stabilization by the pendant phenolic groups.

The group of Nocera extended the investigation of local proton source effect by establishing pendant phenolic and sulfonic groups in an iron hangman porphyrin configuration, 50 shown in catalyst 12 and 13, respectively (Figure 7). The pendant $-\mathrm{OH}$ groups induced a thermodynamically favoured $5.0 \mathrm{kcal} / \mathrm{mol}$ stabilization of the $\mathrm{CO}_{2}$ adduct. However, the introduction of sulfonic groups did not improve the catalytic activity of the system because once deprotonated, they cannot be reprotonated by the weaker external $\mathrm{PhOH}$ donor (the $\mathrm{p} K_{\mathrm{a}}$ of sulfonic acid is 3 and the $\mathrm{p} K_{\mathrm{a}}$ of $\mathrm{PhOH}$ is 18 in $\left.\mathrm{DMF}^{51}\right)$. The steric congestion and electrostatic repulsion from the negatively charged sulfonate group resulted in a mismatch of orientation where the sulfonic group is no longer pointed towards the bound $\mathrm{CO}_{2}$ substrate. This highlights the importance of the external acid source choice in regenerating the pendant local proton groups to maintain the second sphere coordination effect. A reference catalyst $\mathbf{1 4}$ lacking the hanging group showed similar activities as that of the modified iron hangman porphyrins indicating that dibenzofuran clefts in $\mathbf{1 2}$ and $\mathbf{1 3}$ are not optimized to promote a good $\mathrm{CO}_{2}$ binding.

\subsubsection{Hydrogen-Bond Donors}

Another approach for second coordination effect does not necessarily place local proton sources in the periphery of the catalyst, but places functional groups able to establish hydrogen bonding interactions (Figure 8) either with the metal carboxylate adduct or with the external proton sources to synergistically stabilize $\mathrm{CO}_{2}$ reduction intermediates.

Placing one simple amine function in the ortho position of the meso aryl group in catalyst $\mathbf{1 5}$ slightly improved the catalytic activity ( $\log T O F_{\max }=4.02$ ) but with slightly higher overpotential $\left(\eta^{\prime}=0.76 \mathrm{~V}\right)$ as compared to the nonfunctionalized catalyst $\mathbf{1}$ in the same conditions $\left(\log T O F_{\max }=3.01, \eta=0.74 \mathrm{~V}\right) .{ }^{52}$ However, placing this amino function in the meta position (catalyst 16), increased the overpotential $\left(\eta^{\prime}=0.82 \mathrm{~V}\right)$ but resulted in a lowered catalytic activity $\left(\log T O F_{\max }=3.40\right)$. This indicates that even with the same functional group, a simple position modification can affect the catalytic properties of the system. It seems that the ortho positioning of the amino group is optimal for the stabilization of the metal carboxylate intermediate, having a DFT-calculated distance of $1.97 \AA$ for $(\mathrm{N}) \mathrm{H} \cdots \mathrm{O}(\mathrm{C})$. An iron hangman porphyrin with guanidinium group (catalyst 17) as $\mathrm{H}$-bond donor was reported by the group of Nocera and showed a thermodynamically favoured $-2.61 \mathrm{kcal} / \mathrm{mol}$ stabilization of the $\mathrm{CO}_{2}$ adduct. ${ }^{50}$ However, the catalytic activity was even poorer $\left(\log T O F_{\max }=2.47, \eta^{\prime}=0.77 \mathrm{~V}\right)$ than the simple amino function, possibly because of the unoptimized dibenzofuran cleft preventing the guanidinium group to be in proper distance with respect to the metal carboxylate intermediate, as it was similarly reasoned for catalysts $\mathbf{1 2}$ and 13.

The group of Chang has systematically studied the importance of the position of amide moieties as hydrogenbond donors in Fe-porphyrins (catalysts 18, 19, 20, 21)..$^{53}$ It was shown that modified Fe-porphyrins with an ortho amide (catalysts 18 and 20, log $T O F_{\max }=4.35$ to $6.74, \eta^{\prime}=0.74$ to 0.80 $\mathrm{V})$ in the meso aryl of the porphyrin perform better than their corresponding analogues with a para configuration (catalysts 19 and 21, $\log T O F_{\max }=2.23$ to $3.84, \eta^{\prime}=0.77$ to $0.78 \mathrm{~V}$ ). Furthermore, a distal positioning (catalyst 18, log $T O F_{\max }=6.74$, $\eta^{\prime}=0.80 \mathrm{~V}$ ) is better than a proximal one (catalyst $20, \log T O F_{\text {max }}$ $\left.=4.35, \eta^{\prime}=0.74 \mathrm{~V}\right) .{ }^{53}$ This shows that proper positioning of the amide functions is critical in establishing suitable hydrogen bonding interactions with the metal carboxylate intermediate. They all improved the catalytic activity of the nonfunctionalized

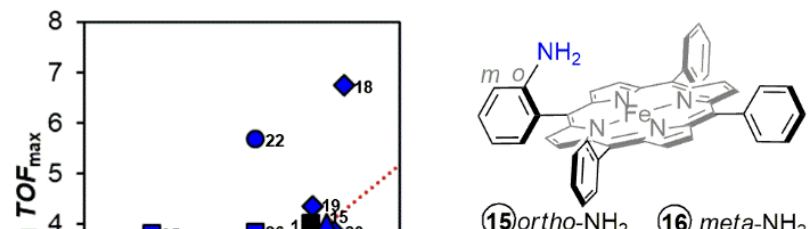

(15)ortho- $\mathrm{NH}_{2}$ (16) meta- $\mathrm{NH}_{2}$
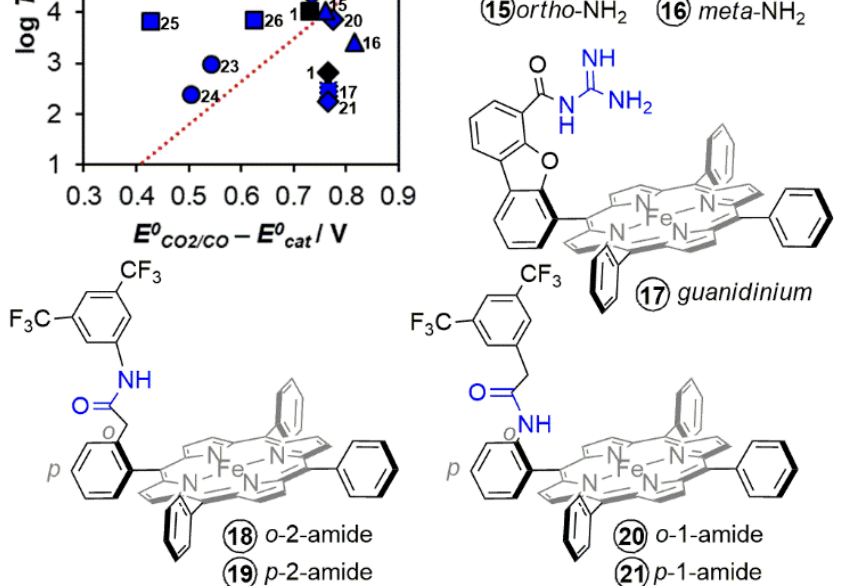

21) $p$-1-amide
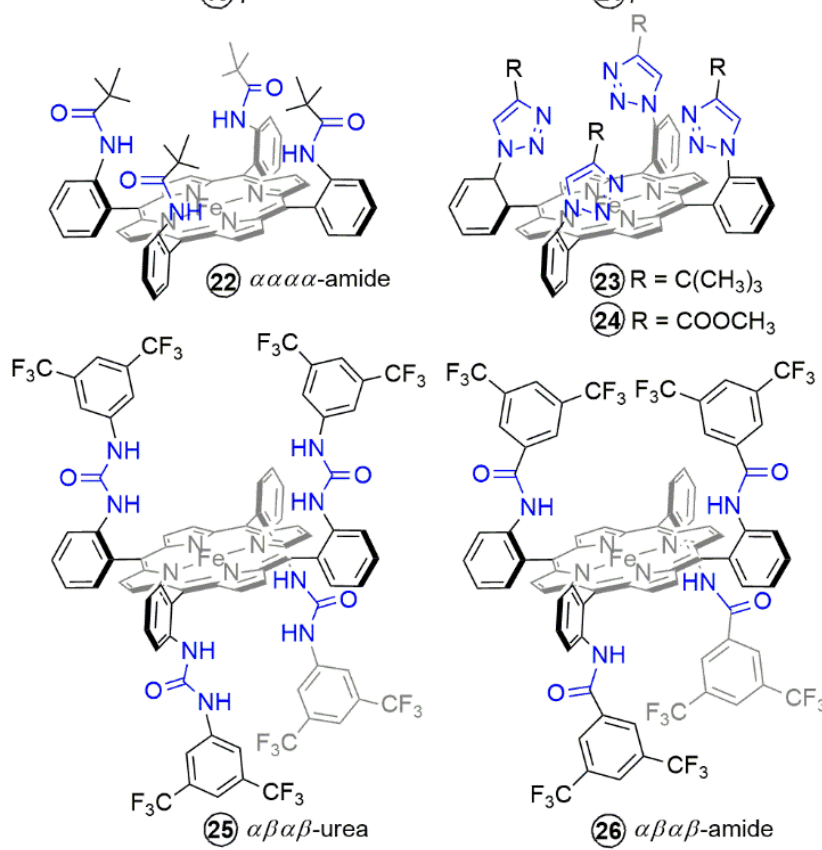

Figure 8. Effect of functional groups acting as hydrogen-bond relay in the second coordination sphere of modified iron porphyrins. Conditions: DMF with $1 \mathrm{M} \mathrm{PhOH}$ (triangle) or $0.1 \mathrm{M} \mathrm{PhOH}$ (diamond) or $0.04 \mathrm{M} \mathrm{PhOH} \mathrm{(dotted} \mathrm{square)} \mathrm{or} 5 \mathrm{M} \mathrm{H}_{2} \mathrm{O}$ (square; $\mathrm{ACN}$ with $3 \mathrm{M} \mathrm{PhOH}$ (circle). Through-structure relation from Figure 5 and performance of nonfunctionalized catalyst $\mathbf{1}$ are shown for relative comparison. 
(a)

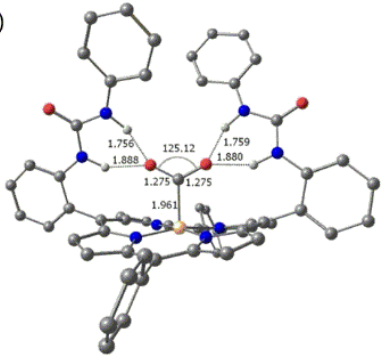

(b)

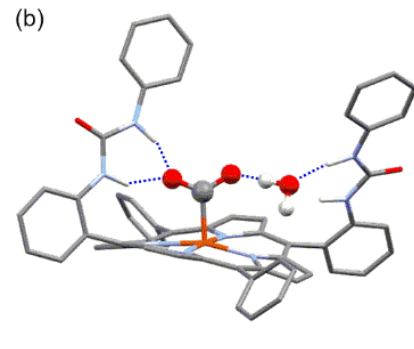

Figure 9. DFT-optimized model structures of (a) $\mathrm{CO}_{2}$ intermediate with triply reduced catalyst $\mathbf{2 5}$ and (b) the synergistic stabilization in presence of a water molecule.

catalyst 1 but the overpotentials were still not significantly lowered. Recently, the group of Dey has synthesized a picket fence iron porphyrin in an $\alpha \alpha \alpha \alpha$ atropoisomer configuration that contains proximal amides, ${ }^{54}$ as shown in catalyst $\mathbf{2 2}$. This catalyst has an improved catalytic rate $\left(\log T O F_{\max }=5.71\right)$ in ACN with $3 \mathrm{M} \mathrm{PhOH}$ while having a lower overpotential $\left(\eta^{\prime}=\right.$ $0.62 \mathrm{~V}$ ) as compared to the that of catalysts with single amide group $(\mathbf{1 8}, \mathbf{1 9}, \mathbf{2 0}, \mathbf{2 1})$. This shows that aside from proper positioning, the number of such pendant amido groups can also affect the catalytic activity of the system.

Our group has taken into account these subtleties and envisioned that putting urea groups (catalyst 25) instead of amido groups would provide multiple-point hydrogen bonding stabilization of the metal carboxylate intermediate. ${ }^{35}$ An $\alpha B \alpha B$ atropoisomer configuration was further considered to provide two sets of hydrogen bonding stabilization in a trans fashion towards the $\mathrm{M}-\mathrm{CO}_{2}$ intermediate, mimicking a similar configuration observed in the active site of CODH. This carefully designed catalyst significantly lowered the overpotential $\left(\eta^{\prime}=\right.$ $0.43 \mathrm{~V}$ ) while maintaining a good log TOF $\max$ (3.83). Comparative study with an analogue catalyst containing amide groups as single-point hydrogen bond donors (catalyst 26) resulted in a similar log TOF $\max (3.85)$ but with a higher overpotential $\left(\eta^{\prime}=\right.$ $0.63 \mathrm{~V})$, underlying the importance of the multi-point stabilization offered by the urea groups. More detailed study based on observations from X-ray crystal structures of the catalysts and DFT calculations have revealed that indeed both $\mathrm{N}-\mathrm{H}$ fragments of each urea arm establish strong hydrogen bonding with the metal carboxylate intermediate with short (N) $\mathrm{H} \cdots \mathrm{O}$ (C) donor-acceptor distances of $1.76-1.88 \AA$ (Figure 9a). These distances are very similar to those reported for hydrogen bond distances between lysine and histidine residues and the $\mathrm{CO}_{2}$ adduct in the active site of $\mathrm{CODH}$ (Figure 6).

Kinetic and isotope-effect studies revealed that, unlike for previously described catalysts that require acidic proton sources (e.g. phenol, trifluoroethanol) for enhanced catalytic activity, water is a sufficient proton source for catalyst $\mathbf{2 5}$ and water molecules seem to work in synergy with the urea groups to provide higher catalytic activity. It was further evidenced by DFT calculations that a water molecule can be inserted between the $\mathrm{M}-\mathrm{CO}_{2}$ adduct and one urea arm with almost unchanged topology of the $\mathrm{CO}_{2}$ intermediate (Figure 9b). Similar strategy of trapping and leveraging water molecules in the triazole groups of catalyst $\mathbf{2 3}$ and $\mathbf{2 4}$ was utilized by the group of Dey to indirectly establish stabilization of the $\mathrm{CO}_{2}$ intermediate. ${ }^{54}$
When compared to the catalyst bearing urea groups 25 , catalyst 23 and 24 showed a small effect on the overpotential $\left(\eta^{\prime}=0.50\right.$ to $0.54 \mathrm{~V})$ and catalytic activity ( $\log T O F_{\max }=2.4$ to 3.0 ). The aforementioned results emphasise the importance of a proper $\mathrm{H}$-bond donors' positioning and number in the vicinity of the $\mathrm{CO}_{2}$ intermediate to establish a direct and efficient $\mathrm{H}$-bonding stabilization that can improve the catalytic activity of the system. Unlike in the case of local proton sources, local H-bond donors can work in synergy with external proton sources to enhance the catalytic activity.

\subsubsection{Cationic Moieties}

The observation that once the nearby amino acid residues in the active site of $\mathrm{CODH}$ are protonated, they establish a cationic environment that can stabilize the $\mathrm{CO}_{2}$ intermediate (Figure 6), hinted the possibility of tethering charged groups in the periphery of the iron porphyrin platform (Figure 10). Indeed, substantial improvements were observed with the incorporation of cationic functionalities like trimethylammonium groups (catalysts 27 and 28) in iron porphyrin catalysts reported by the group of Robert, Costentin and Savéant. ${ }^{34}$ The ortho-positioning (catalyst 27) of these groups is optimal for through-space electrostatic interactions between the positive charges of substituents and the negative charge of the metal carboxylate intermediate and thus resulted in a significant decrease in overpotential $\left(\eta^{\prime}=0.25 \mathrm{~V}\right)$ while simultaneously increasing the TOF $\left(\log\right.$ TOF $\left._{\max }=6\right) .{ }^{18}$ Placing trimethylammonium groups in the para position lead to a catalyst (28) exhibiting a higher overpotential $(\eta=0.57 \mathrm{~V})$ and lower catalytic activity $\left(\log T O F_{\max }=4.4\right)$, highlighting the importance of suitable orientation of these through-space electrostatic effects. A similar improvement was observed for a picket fence catalyst $\mathbf{3 0}$ containing the synergistic effects of
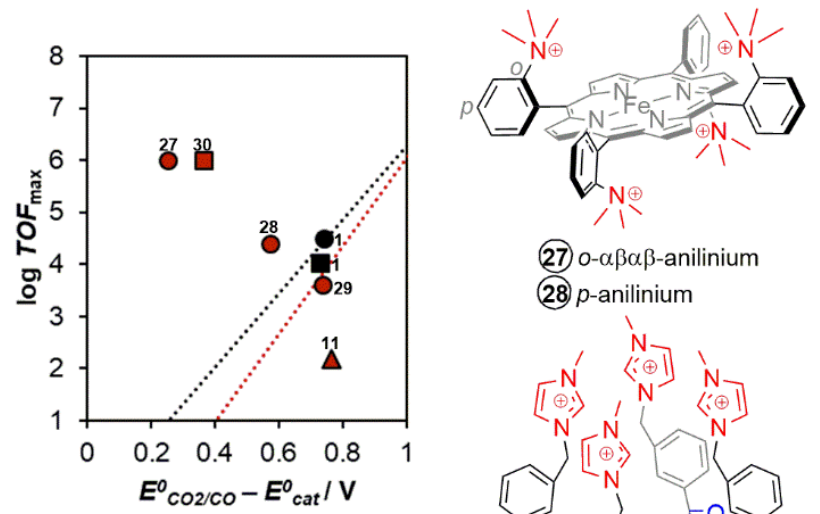

(27) $0-\alpha \beta \alpha \beta$-anilinium (28) $p$-anilinium

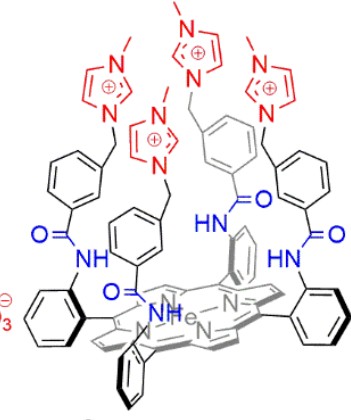

(30) $\alpha \alpha \alpha \alpha$-imidazolium

Figure 10. Effect of charged functional groups in the second coordination sphere of modified iron porphyrins. Conditions: DMF with $3 \mathrm{M} \mathrm{PhOH}$ (circle) or $0.04 \mathrm{M} \mathrm{PhOH}$ (triangle) or $5 \mathrm{M} \mathrm{H}_{2} \mathrm{O}$ (square). Through-structure relation from Figure 5 and performance of nonfunctionalized catalyst $\mathbf{1}$ are shown for relative comparison. 
cationic methylimidazolium groups and proximal amido groups acting as $\mathrm{H}$-bond donors, resulting in a similarly improved catalytic performance $\left(\log T O F_{\max }=6, \eta^{\prime}=0.37 \mathrm{~V}\right) .^{36}$

Because of the cationic charges in these catalysts, they were also reported to have even higher catalytic performances in water as a solvent and proton source, which is a major advancement toward more sustainable conversion of $\mathrm{CO}_{2}$ Catalyst $\mathbf{2 8}$ shows high stability and catalytic activity in a quasineutral aqueous $\mathrm{KCl}$ solution $(\mathrm{pH}=6.7)$ at an applied potential of $-0.86 \mathrm{~V}$ vs. NHE. In a controlled potential electrolysis, the system maintains a Faradaic efficiency for $\mathrm{CO}$ production higher than $98 \%$ for over 72 h. ${ }^{55}$ Recently, the same catalyst was also reported by the group of Robert to photo-catalytically reduce $\mathrm{CO}_{2}$ to $\mathrm{CH}_{4}$ when coupled to an Ir-based ${ }^{56,57}$ or organic photosensitizer. ${ }^{58}$ Catalyst $\mathbf{3 0}$ similarly showed good electrocatalytic activity and selectivity in water, resulting in 91 \% Faradaic efficiency for CO production at $-0.95 \mathrm{~V}$ vs. NHE. Although catalyst $\mathbf{2 7}$ has the best performance so far in terms of log TOF max and overpotential as shown in Figure 10, there are no reported bulk electrocatalysis data in purely aqueous solution though it exhibited $100 \%$ Faradaic efficiency over $84 \mathrm{~h}$ electrocatalysis in DMF solution containing $3 \mathrm{M} \mathrm{PhOH}$ and 0.1 $\mathrm{M} \mathrm{H}_{2} \mathrm{O} .{ }^{34}$

The incorporation of negatively-charged sulfonate substituents (catalyst 29), on the other hand, resulted in a decrease in the log $T O F_{\max }$ (3.6) and increase in overpotential $\left(\eta^{\prime}=0.74 \mathrm{~V}\right)$ as a result of electrostatic repulsions with the negatively charged metal carboxylate intermediate. ${ }^{34}$ This was similarly observed for an iron hangman porphyrin containing sulfonic acid groups (catalyst 11), which were immediately deprotonated in solution causing electrostatic repulsion of the sulfonate group away from the $\mathrm{CO}_{2}$ intermediate. ${ }^{50}$ These negative effects are clearly observed in the relative positioning of the performance of these catalysts towards the downward right part from the linear scaling in Figure 10.

\subsubsection{Bimetallic Design}

Another approach for secondary coordination effect is through the bimetallic approach which has been similarly observed in [NiFe]-centred $\mathrm{CODH}$ enzymes. The bimetallic system works cooperatively to store charges and to activate the $\mathrm{CO}_{2}$ substrate in a classical push-pull donor-acceptor configuration. Naruta and co-workers developed a cofacial homobimetallic complex based on the well-known $\mathrm{CO}_{2}$-reducing iron porphyrin catalysts (Figure 11). ${ }^{59}$ Taking advantage of the rigidity of the porphyrin platforms and the modularity of a phenyl linker, they were able to control the distance between the two Fe metal centres. Compared to the monomeric catalyst 1 , a higher catalytic activity $\left(\log T O F_{\max }=4.3\right.$, Faradaic efficiency $=95 \%$, and $\eta^{\prime}=$ $0.71 \mathrm{~V}$ ) was achieved with an ortho configuration of the dimer (catalyst 31) where the Fe-Fe distance is expected to be $3.2-$ 4.0 $\AA$, suitable for the binding of the $\mathrm{CO}_{2}$ substrate. Cyclic voltammetry studies show overlapping formal reductions of the two iron porphyrin catalysts, with the onset of the catalytic activity corresponding to the $\mathrm{Fe}^{\mathrm{l} / 0}$ redox couple. The overpotential and catalytic activity of the system was further
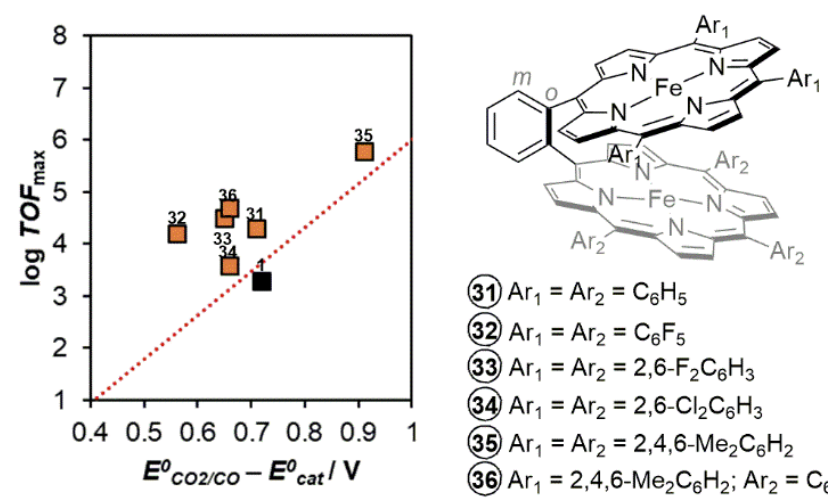

(31) $\mathrm{Ar}_{1}=\mathrm{Ar}_{2}=\mathrm{C}_{6} \mathrm{H}_{5}$ (32. $\mathrm{Ar}_{1}=\mathrm{Ar}_{2}=\mathrm{C}_{6} \mathrm{~F}_{5}$ (33) $\mathrm{Ar}_{1}=\mathrm{Ar}_{2}=2,6-\mathrm{F}_{2} \mathrm{C}_{6} \mathrm{H}_{3}$ (34) $\mathrm{Ar}_{1}=\mathrm{Ar}_{2}=2,6-\mathrm{Cl}_{2} \mathrm{C}_{6} \mathrm{H}_{3}$ (35) $\mathrm{Ar}_{1}=\mathrm{Ar}_{2}=2,4,6-\mathrm{Me}_{2} \mathrm{C}_{6} \mathrm{H}_{2}$ (36) $\mathrm{Ar}_{1}=2,4,6-\mathrm{Me}_{2} \mathrm{C}_{6} \mathrm{H}_{2} ; \mathrm{Ar}_{2}=\mathrm{C}_{6} \mathrm{H}_{5}$

Figure 11. Effect of bimetallic strategy in the second coordination sphere of modified iron porphyrins. Condition: DMF with $5 \mathrm{M} \mathrm{H}_{2} \mathrm{O}$. Through-structure relation from Figure 5 and performance of monomeric catalyst 1 are shown for relative comparison.

optimized using through-structure substituent effects (catalysts 32, 33, 34, 35, 36). 60 Introducing electron-withdrawing substituents on the phenyl rings of the porphyrin (catalyst $\mathbf{3 2}$ ) lowers the catalytic reaction overpotential $\left(n^{\prime}\right)$ to $0.56 \mathrm{~V}$ with a $\log T O F_{\max }$ of 4.2. Introducing electron donating groups (catalyst 35 ), on the other hand, resulted in higher catalytic activity (log TOF $\left.F_{\text {max }}=5.8\right)$ at a cost of higher overpotential $\left(\eta^{\prime}=0.91 \mathrm{~V}\right)$.

\subsection{Opportunities for Future Design Modifications}

The various synthetic routes to modify the iron tetraphenyl porphyrin platform has paved the way to several improvement strategies, as summarized in Figure 12. The goal of all these strategies is to improve the overpotential and the catalytic turnover frequency of the system, without sacrificing the $\mathrm{CO}_{2}$ to-CO selectivity and the Faradaic efficiency of the parent catalyst. Through-structure substituent effects (black circles, Figure 12) shows a linear scaling relationship between the overpotential and the catalytic turnover frequency, where lower overpotentials are observed with electron-withdrawing groups (albeit with lower catalytic activity), and higher catalytic activities are achieved when electron-donating groups are introduced on the periphery of the catalyst (albeit with higher overpotentials). Second coordination sphere modifications can easily break away from this linear scaling relationship. Employing a bimetallic approach (orange circles, Figure 12) with

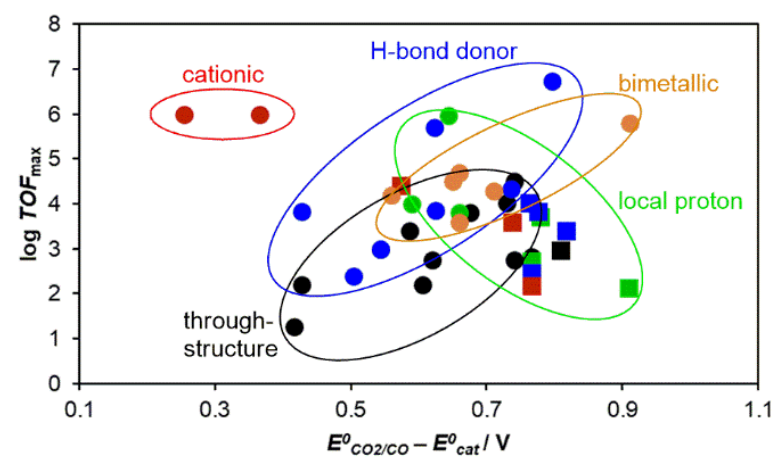

Figure 12. Summary of the catalytic performances of iron porphyrins modified with various design strategies. (Circles represent optimized effect while squares represent unoptimized strategy due to improper positioning, number, and functional nature). 
cofacial iron porphyrins slightly improves the catalytic activities but with no significant changes in the overpotentials, although the latter can easily be tuned by the classical through-structure electronic effects. Installing local proton sources (green circles, Figure 12) in the vicinity of the ligand framework initially showed great promise in improving the catalytic activity and to some extent lowering the overpotential, but careful choice of catalytic conditions (solvent and proton source) are needed to ensure instalment of proton-transfer and hydrogen bond-relay effects (unoptimized reinforcements shown in green squares). Tethering simple hydrogen bond donors, such as amino, amido, and urea functions (blue markers, Figure 12) is another successful strategy because these functions seldom compete with external proton sources, and instead operate in synergy with the proton sources during the catalytic reaction. Great attention should also be given to the proper positioning of the above-mentioned relays to maximize the performances of the catalyst (unoptimized reinforcement shown in blue squares). Lastly, it seems that significant improvements are observed when placing cationic moieties in the vicinity of the porphyrin platform (red markers) that significantly lowers the overpotential while improving the catalytic activity and further making it possible to perform the catalysis in water.

Though most of the studies presented here have focused in the modifications of the iron tetraphenylporphyrin, similar modifications can also be found in other porphyrin catalysts, though not as extensive (Figure 13). Early studies of cobaltbased porphyrins with carboxylic acid (catalyst 37) or sulfonic acid functions (catalyst $\mathbf{3 8}$ ) in the meso aryl groups showed electrocatalytic reduction of $\mathrm{CO}_{2}$ to formic acid in aqueous solutions, though the products were not quantified. ${ }^{19} \mathrm{~A}$ cobalt tetraphenyl porphyrin (CoTPP, catalyst 39) was similarly reported to show enhanced catalytic currents under $\mathrm{CO}_{2}$ with the onset of the catalytic current occurring at the Co'TPP/Co ${ }^{\circ}$ TPP redox couple $(-2.02 \mathrm{~V}$ vs. SCE in butyronitrile solution), however controlled electrolysis and identification of products were not pursued. ${ }^{61}$ Interestingly, a cofacial metalloporphyrin was self-assembled using electrostatic interactions between a cationic Co-5,10,15,20-tetrakis(4methylpyridyl)porphyrin and an anionic Co-5,10,15,20tetrakis(4-sulfonatophenyl)porphyrin (catalyst 43 ), and showed

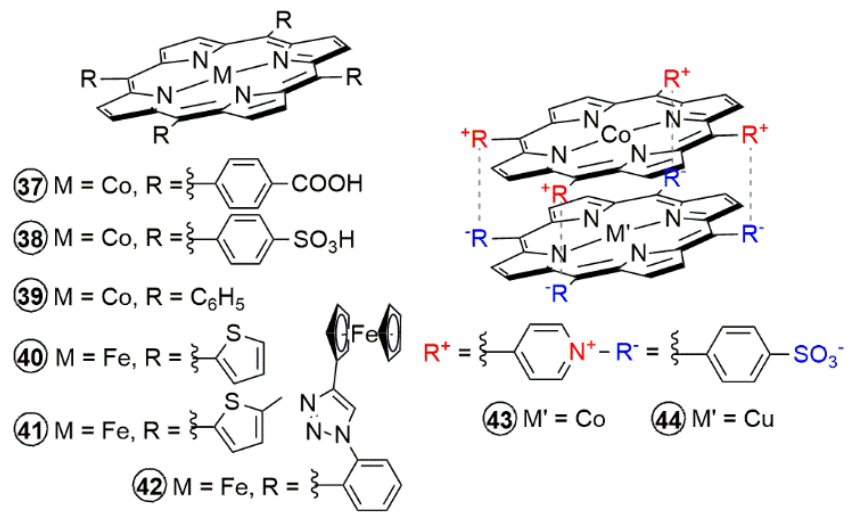

Figure 13. Other modifications of metalloporphyrin-based molecular catalysts for $\mathrm{CO}_{2}$ reduction, showing future opportunities for catalyst improvement. catalytic $\mathrm{CO}_{2}$ reduction activity at $-1.80 \mathrm{~V} v \mathrm{vs} . \mathrm{Ag} / \mathrm{Ag}^{+}$, forming $\mathrm{CO}$ and formaldehyde, with traces of $\mathrm{H}_{2} .62$ The activity was attributed presumably to $\mathrm{Co}(\mathrm{I})$ of the cationic porphyrin as the anionic counterpart only acted as electron mediator. Changing the metal ion of the electron mediator with $\mathrm{Cu}$ (a mixed $\mathrm{Co}-\mathrm{Cu}$ complex in catalyst 44) resulted in higher catalytic current densities.

Aside from varying the nature of the central metal ion, a recent study by the group of Welch has also reported thienylsubstituted porphyrins (catalyst $\mathbf{4 0}$ and $\mathbf{4 1}$ ), going away with the usual meso aryl groups. Compared to iron tetraphenylporphyrins (1), both catalysts operate at $150 \mathrm{mV}$ lower overpotential, which is attributed to the extension of the $\pi$-conjugation in thienyl-porphyrins, wherein the stabilizing mesomeric effects overcome any destabilizing inductive effects associated with the thiophene being more electron-rich than the phenyl groups. ${ }^{63}$ The catalytic activity is slightly lower compared to $\mathbf{1}$ with a log $T O F_{\max }=3.78$ for catalyst $\mathbf{4 0}$ and log $T O F_{\max }=3.45$ for catalyst $\mathbf{4 1}$. Interestingly, controlled potential electrolysis showed lower TON $=\mathbf{1 0}$ for catalyst $\mathbf{4 0}$ due to oxidative electropolymerization of thiopene units on the counter electrode, a phenomenon that can be perceived to be useful in surface immobilization of the catalyst (see the next chapter on heterogenous catalysis). This degradation process was prevented by protecting the vulnerable position of thiopene units by a methyl group in catalyst $\mathbf{4 1}$, resulting in a three-fold increase in TON. Recently, the group of Dey has also reported an iron porphyrin catalyst bearing four ferrocene moieties (catalyst 42) that made it possible to reduce $\mathrm{CO}_{2}$ to $\mathrm{CO}$ in the presence of dioxygen. ${ }^{64}$ The dioxygen tolerant activity stems from (i) the role of ferrocene groups acting as redox fuse for the reduction of dioxygen to benign water, and (ii) the intrinsic 500 times faster rate of reaction of the $\mathrm{Fe}^{0}$ active form of the catalyst towards $\mathrm{CO}_{2}$ substrates as compared to $\mathrm{O}_{2}$ substrates, even though the latter has higher driving force. All these recent developments point to many opportunities and avenues of catalyst design improvement for such a tuneable and efficient porphyrin platform towards $\mathrm{CO}_{2}$ reduction.

\section{Heterogenous $\mathrm{CO}_{2}$ Reduction}

Homogenous catalysis offers two main advantages. The first is the relative ease to tune synthetically the structure and therefore the physical properties of the catalyst in order to modulate the performances of the catalytic system, and the second is the better compatibility of the homogenous conditions with the different spectroscopic methods employed to detect and characterize reactive intermediates, which facilitate the elucidation of the mechanistic details of the catalytic reaction. As mentioned earlier, metalloporphyrin catalysts for $\mathrm{CO}_{2}$ reduction were mainly studied in the context of molecular electrocatalysis. However, homogeneous catalysts present in the electrolyte can only be electro-activated in the first diffusion layer at the surface of the cathode. Heterogeneous molecular electrocatalysis offers the possibility of overcoming this and other drawbacks such as slow multielectron transfer steps to the catalyst often associated 
with molecular homogeneous electrocatalysis. Dimerization or aggregation of the homogenous catalysts are among the first drawbacks that come to mind because they can significantly reduce the durability (the lifetime) of the catalytic system. ${ }^{65}$ Immobilizing molecular catalysts at the surface of an electrode for heterogeneous molecular electrocatalysis may circumvent these intrinsic limitations as compared to homogeneous studies. ${ }^{66}$ Heterogenization also permits the transfer of the electrocatalytic studies in solvents such as water that otherwise could not be employed because of the low solubility of

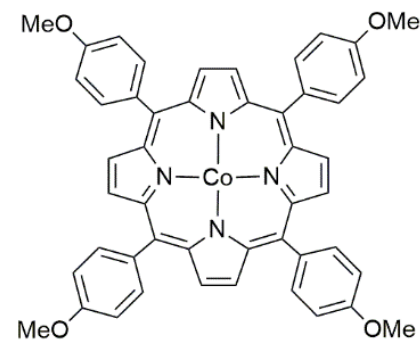

(45)

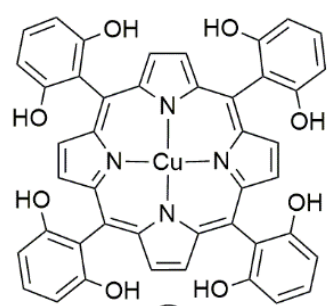

(47)

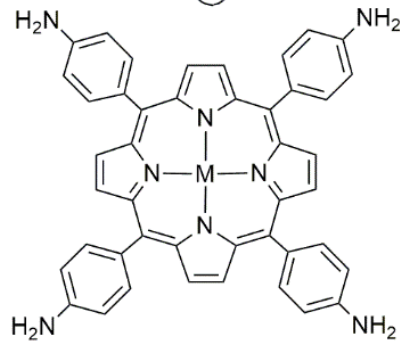

(49) $\mathrm{M}=\mathrm{Co}(50 \mathrm{M}=\mathrm{Fe}$ (51) $\mathrm{M}=\mathrm{Zn}$

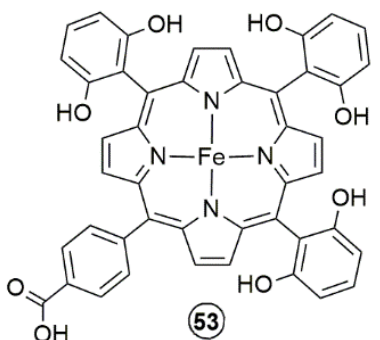

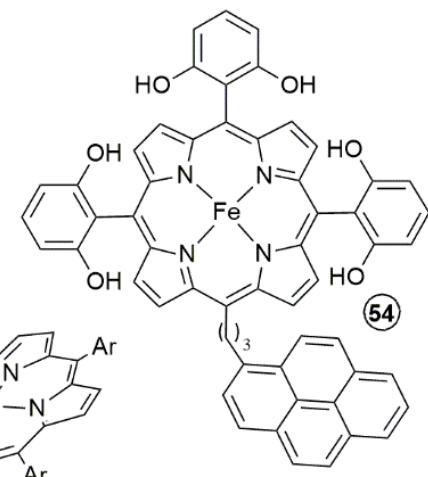

(52)

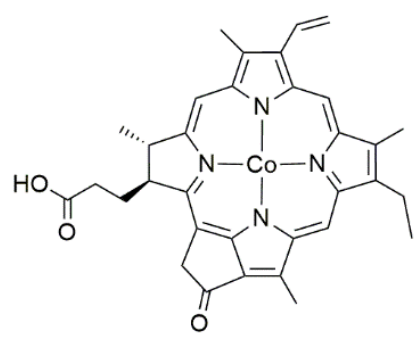

(48)

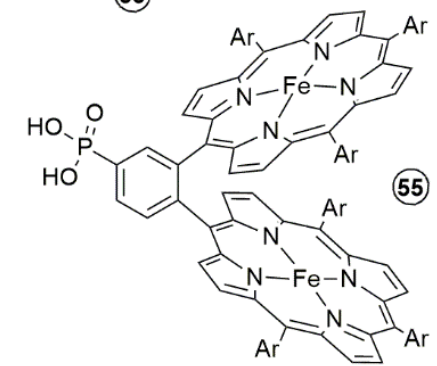

Figure 14. Metalloporphyrins used in the preparation of modified cathodes for the heterogeneous electrocatalytic reduction of $\mathrm{CO}_{2}$. metalloporphyrins in aqueous medium. ${ }^{67}$ An important aspect to bear in mind for the development of electrolysers that can couple, for example, $\mathrm{CO}_{2}$ reduction with water oxidation to dioxygen, ${ }^{68}$ is the compartmentalization of the cathodic and anodic processes. The immobilization of molecular $\mathrm{CO}_{2}$ reduction catalyst on the cathode or water oxidizing catalysts on the anode is currently investigated to develop chemically modified cathodes and anodes.

Carbon-based electrodes including glassy carbon (GC) electrodes, activated carbon fibers (ACF), gas diffusion electrodes (GDE), carbon paper, pyrolitic graphite (PG) electrodes, and carbon fabric electrodes are especially suitable as a cathode for the immobilization of molecular $\mathrm{CO}_{2}$ reduction catalysts because of their high overpotential for the competing hydrogen production and their stability under reduction conditions. Since the first report by the group of Aramata on the catalytic $\mathrm{CO}_{2}$ reduction by a CoTPP fixed on a glassy carbon electrode through a 4-aminopiridine linker, ${ }^{69}$ several examples of heterogeneous electrocatalytic systems based on the immobilization of metalloporphyrins, almost exclusively on carbon-based electrodes, were reported. Here we will present a brief overview of the different methods developed to prepare these modified electrodes and their catalytic activity towards $\mathrm{CO}_{2}$ reduction.

\subsection{Electrode Modification by Adsorption}

Chemisorption is certainly the most convenient and straightforward technique to immobilize metalloporphyrins on the surface of carbonaceous electrodes. The spontaneous noncovalent modification of the electrode surface stems from the strong affinity of the delocalized $\pi$ conjugated systems of these macrocycles. These modified electrodes were shown to be stable enough for long periods in a solvent where the catalyst is not soluble. The group of Sakata reported in 1999 the electrochemical reduction of $\mathrm{CO}_{2}$ at $\mathrm{Co}-, \mathrm{Fe}-, \mathrm{Ni}-, \mathrm{Zn}-$ and $\mathrm{Cu}-\mathrm{TPP}$ supported gas diffusion electrodes (GDE) under high pressure of $\mathrm{CO}_{2} \cdot{ }^{70}$ An average of $6 \times 10^{-8} \mathrm{~mol} / \mathrm{cm}^{2}$ catalyst surface concentration on the GDE was obtained by impregnation of the electrode using a dichloromethane solution of the different catalysts. Under 20 atm pressure of $\mathrm{CO}_{2}$ all these catalysts produced a mixture of $\mathrm{CO}, \mathrm{H}_{2}$, and $\mathrm{HCOOH}$ but only $\mathrm{Co}$ - and $\mathrm{Fe}-$ TPP were able to reach over $80 \%$ Faradaic efficiency for $\mathrm{CO}_{2}$ reduction and over $80 \%$ selectivity for $\mathrm{CO}$ production. It was reported later that combining GDE and activated carbon fibers to immobilize Co-5,10,15,20-tetrakis(4-methoxyphenyl)porphyrin (45, Figure 14) can increase significantly the catalyst concentration on the electrode to reach a current density for CO production as high as $50-70 \mathrm{~mA} / \mathrm{cm}^{2}$ with over $85 \%$ selectivity at atmospheric $\mathrm{CO}_{2}$ pressure.

Using pyrolitic graphite (PG) electrodes to dock Coprotoporphyrin catalysts (46, Figure 14), the group of Koper reported the electrochemical reduction of $\mathrm{CO}_{2}$ in acidic aqueous media $(\mathrm{pH} 1-3)$ to produce $\mathrm{CO}$ with current densities of 0.08 and $0.16 \mathrm{~mA} / \mathrm{cm}^{2}$ for $1 \mathrm{~h}$. This corresponds to TOFs of ca. 0.2 and $0.8 \mathrm{~s}^{-1} .^{71}$ More importantly, in these acidic conditions, small 
amount of methane and trace amounts of $\mathrm{HCOOH}$ and methanol were detected.

A remarkably higher production of multi-electron reduction productions was later reported by the groups of Brudvig and Wang using chemisorbed Cu-5,10,15,20-tetrakis(2,6dihydroxyphenyl)-porphyrin (47, Figure 14) on carbon nanoparticles coated carbon fiber paper. ${ }^{72} \mathrm{At}-0.976 \mathrm{~V}$ vs. NHE, in addition to $\mathrm{CO}$, the catalyst was able to drive partial current densities of 13.2 and $8.4 \mathrm{~mA} / \mathrm{cm}^{2}$, corresponding to TOFs of 3.4 and 1.8 site $^{-1} \mathrm{~s}^{-1}$ for methane and ethylene production from $\mathrm{CO}_{2}$ reduction corresponding to a Faradaic efficiency of $44 \%$ for these two products. Using the same technique to immobilize Zn-5,10,15,20-tetrakis-mesitylporphyrin (48, Figure 14), these authors have argued that the electrocatalytic reduction of $\mathrm{CO}_{2}$ originated from the non-innocent electrochemical reactivity of the porphyrinic ligand. ${ }^{73}$ In fact, despite the redox-inactivity of the zinc within the potential window of the catalysis, $\mathrm{CO}$ was produced with a Faradaic efficiency of $95 \%$ at $-1.7 \mathrm{~V} v$ s. SHE and a TOF as high as 14 site $^{-1} \mathrm{~s}^{-1}$.

\subsection{Electrode Modification by Electropolymerization}

By introducing the appropriate groups on the periphery of the porphyrin macrocycle, the corresponding catalyst can be easily supported on an electrode using electropolymerization. Co-, Feand $\mathrm{Zn-5,10,15,20-tetrakis(4-aminophenyl)porphyrin} \mathrm{(49,50}$ $\mathbf{5 1}$, Figure 14) were used by the group of Issacs in potentiodynamic cycles to grow polymeric films on an ITO electrode. ${ }^{74,75}$ The electrocatalytic properties toward $\mathrm{CO}_{2}$ reduction of these three catalysts were evaluated in a $\mathrm{BMImBF}_{4}$ (1-butyl-3methylimidazolium tetrafluoroborate) ionic liquid as a novel electrolyte for $\mathrm{CO}_{2}$ electroreduction. All catalysts produced $\mathrm{CO}$ at particularly low overpotentials, $-0.8 \mathrm{~V}$ vs. $\mathrm{Ag} / \mathrm{AgCl}$, but while the electropolymerized Co- and Fe-porphyrin exhibit respectively $67 \%$ and $78 \%$ Faradaic efficiency, the corresponding Zn-based catalyst shows only $15 \%$ Faradaic efficiency.

\subsection{Electrode Modification Using Multi-Walled Carbon Nanotubes and Nafion ${ }^{\circledR}$ Membrane}

The combination of multi-walled carbon nanotubes (MWCNTs) and Nafion ${ }^{\circledR}$ has recently emerged as another technique of choice for a rapid preparation of modified electrodes with molecular catalysts of high surface areas. ${ }^{68,76-78}$ The Nafion $^{\circledR}$ polymeric membrane holds the molecular catalyst-impregnated MWCNTs attached to the surface of the electrode while offering high proton permeability as well as effective access of the substrate $\left(\mathrm{CO}_{2}\right)$ to the membrane-catalyst-electrode layers where the electrochemical reaction takes place. The molecular catalyst can be mechanically (e.g. ultrasound mixing in a solution of the catalyst) or covalently introduced in the MWCNTs. Using the first method, Fukuzumi and coworkers prepared a glassy carbon modified electrode by drop casting a sonicated acetonitrile solution containing a Co-chlorin (52, Figure 14), MWCNTs and Nafion ${ }^{\circledast} .{ }^{76} \mathrm{CO}$ and $\mathrm{H}_{2}$ were produced using this modified electrode in an aqueous buffer $(\mathrm{pH}=4.6)$ solution at $-1.1 \mathrm{~V} v$ s. NHE with $89 \%$ and $11 \%$ Faradaic efficiency, respectively. The catalysis reaches a maximum TON of 1,100 and TOF of 2.3 site $^{-1} \mathrm{~s}^{-1}$. A pyrene-appended Fe-porphyrin bearing six pendant $\mathrm{OH}$ groups on the phenyl rings in all ortho and ortho' positions (54, Figure 14) was also immobilized on carbon nanotubes via noncovalent interactions and further deposited on glassy carbon electrode. ${ }^{79}$ The obtained carbon material had an active-catalyst surface concentration of $2.4 \mathrm{x}$ $10^{-8} \mathrm{~mol} / \mathrm{cm}^{2}$ and exhibited highly selective and rapid electroreduction of $\mathrm{CO}_{2}$ to $\mathrm{CO}$ in water $(\mathrm{pH} 7.3)$ at $-1.03 \mathrm{~V} v \mathrm{~s}$. NHE. Catalysis could be sustained for more than 3 hours with 97 $\%$ total Faradaic efficiency and $96 \%$ selectivity for CO production with a TON $=480$ and a TOF $=0.4 \mathrm{site}^{-1} \mathrm{~s}^{-1}$. Employing a similar procedure, Fe-5,10,15,20-tetrakis(4-(trimethylamino)phenyl)-porphyrin (28, Figure 10) was incorporated into a carbon paper-based cathode in a complete electrochemical cell, coupling $\mathrm{CO}_{2}$ reduction to water oxidation. ${ }^{68}$ The analysis of electrolysis products at a cathodic potential of $-0.86 \mathrm{~V} v$ s. NHE for several hours in quasi-neutral water showed Faradaic efficiencies of $90 \%$ for $\mathrm{CO}$ along with $10 \%$ of $\mathrm{H}_{2}$ in the cathodic compartment and $99 \%$ for $\mathrm{O}_{2}$ in the anodic compartment. In two different studies by the groups of Robert ${ }^{77}$ and Han, ${ }^{78}$ the covalent attachment of a Fe- or Co-porphyrin (53 and 46 respectively in Figure 14) catalysts on the MWCNTs was reported to improve significantly the long-term stability of the catalysis while maintaining a good selectivity for $\mathrm{CO}$ production at reasonably low overpotentials.

Even in absence of the Nafion ${ }^{\circledR}$ membrane, the group of Daasbjerg reported an enhanced catalytic activity and selectivity (> $90 \%$ ) for CoTPP (39), as compared to the homogenous catalysis, upon straightforward immobilization onto carbon nanotubes and adsorption on glassy carbon. ${ }^{80}$ The electrode has a relatively high catalyst loading $\left(1.7 \times 10^{-7}\right.$ $\mathrm{mol} / \mathrm{cm}^{2}$ ) and can be stable for over $4 \mathrm{~h}$ in bulk electrolysis mode at -1.35 vs. SCE with a current density of $3.2 \mathrm{~mA} / \mathrm{cm}^{2}$, a TON of 1,118 and a TOF of $0.78 \mathrm{site}^{-1} \mathrm{~s}^{-1}$. An organic cage composed of six FeTPPs (1) was also immobilized on MWCNT present on the surface of a glassy carbon electrode without the use of $\mathrm{Nafion}^{\circledR}$, as reported by the group of Chang. ${ }^{81}$ This electrode exhibited a higher porosity compared to that of a similar electrode prepared using a simple FeTPP. It has an active iron center concentration of $3.7 \mathrm{~mol} / \mathrm{cm}^{-2}$ and over $54 \%$ of iron center being active compared to only $38 \%$ for the latter. The electrocatalytic reduction of $\mathrm{CO}_{2}$ using this electrode in aqueous solution ( $\mathrm{pH}=7.3$ ) produced exclusively $\mathrm{CO}$ at $-0.63 \mathrm{vs}$. RHE with higher TON $=55,205$ and TOF $=0.64$ site $^{-1} \mathrm{~s}^{-1}$ in $24 \mathrm{~h}$ than the FeTPP-based electrode $\left(\right.$ TON $=32,770$ and $T O F=0.38$ site $\left.^{-1} \mathrm{~s}^{-1}\right)$. The difference in the catalytic performance between the two electrodes was attributed to the greater exposure of iron sites observed in the porphyrin-cage based catalyst as well as by the potentially greater diffusion and local concentration of $\mathrm{CO}_{2}$ in the hydrophobic cavity. This is due to a better diffusion of the substrate and the electrolyte throughout an array of readily accessible catalytic metal centers as opposed to aggregation of planar FeTPP molecules that can diminish the number of electrochemically accessible and active metal centers. 


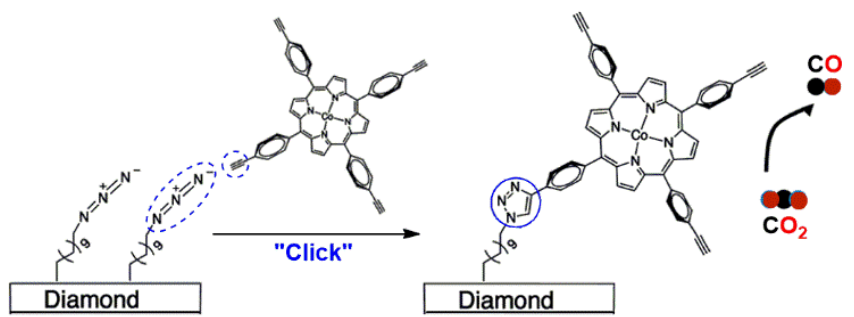

Figure 15. Covalent modification of a diamond cathode surface for the heterogeneous electrocatalytic $\mathrm{CO}_{2}$ reduction. Adapted with permission from Ref. 83 .

\subsection{Covalent Modification of the Electrode}

The functionalization of an electrode surface by means of covalent chemical bond formation was first attempted by the group Aramata. ${ }^{69}$ A glassy carbon electrode was first functionalized using a 4-aminopyridine group then a Co5,10,15,20-tetrakis (4-carboxyphenyl)porphyrin (37, Figure 13) was fixed through the coordination of the pyridine on Co. The modified electrode had a catalyst surface concentration of $10^{-12}$ $\mathrm{mol} / \mathrm{cm}^{2}$ and was able to produce $\mathrm{CO}$ with $50 \%$ Faradaic efficiency at $-1.2 \mathrm{~V}$ vs. SCE in a $\mathrm{CO}_{2}$-saturated standard phosphate buffer solution $(\mathrm{pH}=7)$. Despite this result, some questions still persist about the stability of the Co-pyridine bond in the active reduced and electron-rich form of the catalyst and about the catalyst-role that pyridine itself can play in the electrocatalytic reduction of $\mathrm{CO}_{2} \cdot{ }^{82}$

Recently, a "click" azide-alkyne cycloaddition reaction was employed to directly and covalently attach acetylene groups bearing Co-porphyrin on an azide functionalized boron-doped, p-type conductive diamond electrode (Figure 15).83 The obtained "smart" electrode has a $6.33 \times 10^{-11} \mathrm{~mol} / \mathrm{cm}^{2}$ catalyst coverage and was used for the electrocatalytic reduction of $\mathrm{CO}_{2}$, exhibiting good stability for over 1,000 cycles in the cyclic voltammetry mode with $\mathrm{CO}$ being the main product of the reaction. Naruta and coworkers also reported the covalent grafting of a cofacial bimetalic Fe-porphyrin complex (55, Figure 14) as $\mathrm{CO}_{2}$ reduction catalyst on $\mathrm{SnO}_{2}$ or $\mathrm{TiO}_{2}$ coated fluorinedoped tin oxide (FTO) cathode. ${ }^{84}$ The modified electrode has up to $4.7 \times 10^{-12} \mathrm{~mol} / \mathrm{cm}^{2}$ areal catalyst concetration and can reduce $\mathrm{CO}_{2}$ to $\mathrm{CO}$ in nonaqueous (DMF or ACN) and aqueous solutions. For example, $\mathrm{CO}$ was obtained with a $90 \%$ Faradaic efficiency in neutral water at $-0.95 \mathrm{~V} v$ s. NHE in a $6 \mathrm{~h}$ electrolysis experiment.

\subsection{Electrode Modification by Metal Organic Frameworks (MOFs) or Covalent Organic Frameworks (COFs)}

In both homogenous and heterogeneous catalysis, the first step of the electrocatalytic $\mathrm{CO}_{2}$ reduction by metalloporphyrins is the electron transfer from the cathode to the catalyst, generating the reduced active form, which in turn reacts chemically with $\mathrm{CO}_{2}$ leading eventually to the reaction products. The overall rate of the catalytic reaction, represented by the current density, is governed by both the rate of the reaction between the $\mathrm{CO}_{2}$ and the active species, and the concentration of these species. ${ }^{85,86}$ Unlike in homogenous catalysis, in a heterogeneous system, where the molecular catalyst is immobilized on the electrode surface, the catalysis is not limited by catalyst solubility or its diffusion rate toward the electrode. Thus, higher overall rates for the electrocatalytic reaction at a given applied potential can be achieved by increasing the areal concentration of active catalyst on the electrode. ${ }^{86}$ Of note, limitations in the design of chemically-modified electrodes by impregnation reside in the determination of the number of active sites and also the variability of the active sites owing to partial chemical alteration of the initial catalyst.

Metal-organic framework (MOF) thin films were used to increase the areal concentration of metalloporphyrin catalysts on working electrodes for $\mathrm{CO}_{2}$ reduction. ${ }^{87,88}$ In contrast to a densely packed polymerized film, a MOF creates an ordered, porous heterogeneous network, which allows for free permeation of electrolyte counter ions and dissolved $\mathrm{CO}_{2}$ into the interior of the film. For example, a thin film of Fe-porphyrin based MOF was employed as a platform for anchoring a substantial quantity of the molecular catalyst on a FTO conductive electrode for the electrochemical reduction of $\mathrm{CO}_{2}$ (Figure 16). ${ }^{87}$ The measured surface concentration of the active catalyst $\left(6.2 \times 10^{-8} \mathrm{~mol} / \mathrm{cm}^{2}\right)$ was reported to be much higher than that of the estimated fully packed single layer on a flat surface $\left(7 \times 10^{-11} \mathrm{~mol} / \mathrm{cm}^{2}\right)$. Quasi equal amounts of $\mathrm{CO}$ and $\mathrm{H}_{2}$ were produced using this modified electrode with $100 \%$ Faradaic efficiency at $-1.3 \mathrm{~V}$ vs. NHE with a current density of 5.9 $\mathrm{mA} / \mathrm{cm}^{2}$ for $\sim 3.5 \mathrm{~h}\left(T O N=1,520\right.$ and $T O F=0.13$ site $^{-1} \mathrm{~s}^{-1}$ for CO production) in $1 \mathrm{M}$ trifluoroethanol solution in DMF. Immobilized Co-porphyrin based MOF, exhibiting a $1.1 \times 10^{-7}$ $\mathrm{mol} / \mathrm{cm}^{2}$ areal active-catalyst concentration, was also reported to reduce $\mathrm{CO}_{2}$ in an aqueous solution at $-0.7 \mathrm{~V} v$ s. NHE to produce $\mathrm{CO}$ in excess of $76 \%$ with a current density of 5.9 $\mathrm{mA} / \mathrm{cm}^{2} .88$ The per-site TON obtained for $7 \mathrm{~h}$ electrolysis was 1,400 which correspond to a TOF of 0.56 site $^{-1} \mathrm{~s}^{-1}$.

Covalent organic frameworks (COFs) comprising Coporphyrin catalyst were also deposited as microcrystalline powder on carbon fabric electrode for electrochemical $\mathrm{CO}_{2}$ reduction. ${ }^{89}$ Despite the high porosity and dispersion of Co centers on the electrode, it suffered a low active site ratio, with only $4 \%$ of the total catalyst on the surface, due to aggregation. Nevertheless, this electrode showed exceptional stability for 24 $\mathrm{h}$ and higher selectivity (90\%) and TON (up to 290,000), with initial TOF of 26.1 site $^{-1} \mathrm{~s}^{-1}$ for CO production at low applied potentials $(0.65 \mathrm{~V} v$ s. $\mathrm{NHE})$ in neutral water.

As demonstrated by these last three examples of modified electrodes, MOFs and COFs utilization can increase significantly the areal active-catalyst concentration and thus the catalytic current density. However, a decrease in the catalytic activity can

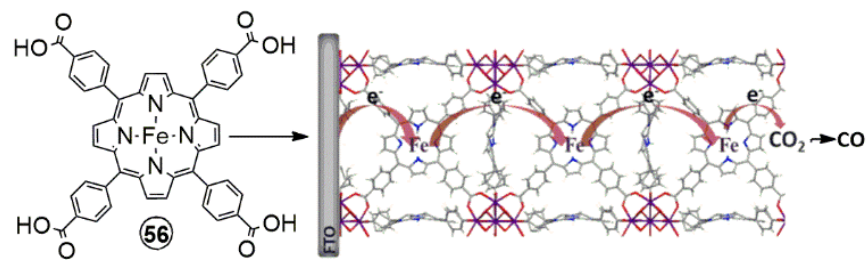

Figure 16. Fe-porphyrin based metal-organic frameworks (MOFs) for the modification of cathodes in the heterogeneous electrocatalytic $\mathrm{CO}_{2}$ reduction. Adapted with permission from Ref. 87. 
be observed for a higher active-site loading due to chargetransport limitation from the electrode to the periphery of MOFs or COFs as the thickness of the film increases. To overcome this limitation, the group of Chang electronically tuned a two-dimensional COF by modification of the reticular structure. ${ }^{90}$ Improved charge transport along the COF backbone was observed, promoting better electronic connectivity between remote functional groups and the active sites, and enables the modulation of the catalytic properties of the system.

\section{Conclusions and Perspectives}

As it transpires from these studies, the porphyrin macrocycle, also termed the pigment of life, ${ }^{91}$ has been a solid brick to construct an excellent molecular component for chemists to activate and reduce $\mathrm{CO}_{2}$ to various reduced forms of carbon. Their implementation in the design of chemically modified electrodes are already leading to highly active materials. Feporphyrin supported on carbonaceous surface has been already tested in lab design electrochemical cell where the reduction of $\mathrm{CO}_{2}$ has been successfully coupled to the water oxidation reaction with exalting global yield. ${ }^{68}$ While their cobalt phthalocyanine congener (another tetrapyrrolic macrocycle not surveyed in this review) was found to rival with referenced $\mathrm{Ag}$ and $\mathrm{Au}$ nanoparticles for the $\mathrm{CO}_{2}$ reduction in a similar complete electrolysis cell. ${ }^{92}$ With such breakthroughs, we can reasonably argue that the decisive focus on molecular catalysis has opened new avenues in this field. One important facet of molecular catalysis is the ability to decipher the intimate steps in the activation of small molecules such as $\mathrm{CO}_{2}$. We can expect in the near future to capture different intermediates to underpin the mechanistic routes that would furthermore help to conduct higher desired selectivity in the $\mathrm{CO}_{2}$ reduction. The development of multimetallic catalysts that can synergistically provide multiple electrons to $\mathrm{CO}_{2}$ should lead to reduced forms of carbon. A particular challenge will be to guide the formation of carbon-carbon bonds for the production of higher carbon containing energy rich compounds. The reactivity routes of molecular catalysts at the surface of electrodes are not an extension of the ones observed in homogeneous medium. The understanding of the enhancement or decrease of surface catalytic activities must be comprehended to provide a rationale for the preparation of optimized chemically modified electrodes. We make no mistake to say that dedicated research at the frontiers between fundamental and applied world must be encouraged with the target to provide rapid solutions to tackle this urgent issue.

\section{Conflicts of interest}

There are no conflicts to declare.

\section{Acknowledgements}

This work was supported by CEA IRTELIS PhD fellowship program (for Dr. P. Gotico.), LabEx CHARMMMAT, and by the French Infrastructure for Integrated Structural Biology (FRISBI) ANR-10-INSB-05-01.

\section{References}

1 R. K. Pachauri and L. A. Meyer, Climate Change 2014: Synthesis Report, Intergovernmental Panel on Climate Change, Geneva, Switzerland, 2014.

2 C. Ampelli, S. Perathoner and G. Centi, Philos. Trans. Royal Soc. A, 2015, 373, 20140177.

3 C. Hepburn, E. Adlen, J. Beddington, E. A. Carter, S. Fuss, N. M. Dowell, J. C. Minx, P. Smith and C. K. Williams, Nature, 2019, 575, 87-97.

4 A. M. Appel, J. E. Bercaw, A. B. Bocarsly, H. Dobbek, D. L. DuBois, M. Dupuis, J. G. Ferry, E. Fujita, R. Hille, P. J. A. Kenis, C. A. Kerfeld, R. H. Morris, C. H. F. Peden, A. R. Portis, S. W. Ragsdale, T. B. Rauchfuss, J. N. H. Reek, L. C. Seefeldt, R. K. Thauer and G. L. Waldrop, Chem. Rev., 2013, 113, 6621-6658.

5 J.-M. Savéant, Chem. Rev., 2008, 108, 2348-2378.

6 N. Elgrishi, M. B. Chambers, X. Wang and M. Fontecave, Chem. Soc. Rev., 2017, 46, 761-796.

7 H. Takeda, C. Cometto, O. Ishitani and M. Robert, ACS Catal., 2017, 7, 70-88.

8 A. Glüer and S. Schneider, J. Organomet. Chem., 2018, 861, 159173.

9 R. Francke, B. Schille and M. Roemelt, Chem. Rev., 2018, 118, 4631-4701.

10 C. Jiang, A. W. Nichols and C. W. Machan, Dalton Trans., 2019, 48, 9454-9468.

11 F. Franco, S. Fernández and J. Lloret-Fillol, Curr Opin Electrochem, 2019, 15, 109-117.

12 K. E. Dalle, J. Warnan, J. J. Leung, B. Reuillard, I. S. Karmel and E. Reisner, Chem. Rev., 2019, 119, 2752-2875.

13 E. Anxolabéhère-Mallart, J. Bonin, C. Fave and M. Robert, Dalton Trans., 2019, 48, 5869-5878.

14 F. A. Walker and U. Simonis, in Encyclopedia of Inorganic Chemistry, American Cancer Society, 2006.

15 C. Costentin, S. Drouet, M. Robert and J.-M. Savéant, J. Am. Chem. Soc., 2012, 134, 11235-11242.

16 C. Costentin, M. Robert and J.-M. Savéant, Chem. Soc. Rev., 2013, 42, 2423-2436.

17 C. Costentin and J.-M. Savéant, ChemElectroChem, 2014, 1, 1226-1236.

18 C. Costentin and J.-M. Savéant, Nat. Rev. Chem., 2017, 1, 0087.

19 K. Takahashi, K. Hiratsuka, H. Sasaki and S. Toshima, Chem. Lett., 1979, 8, 305-308.

20 M. Hammouche, D. Lexa, J. M. Savéant and M. Momenteau, J.

Electroanal. Chem. Interfacial Electrochem., 1988, 249, 347-351.

21 C. Römelt, J. Song, M. Tarrago, J. A. Rees, M. van Gastel, T. Weyhermüller, S. DeBeer, E. Bill, F. Neese and S. Ye, Inorg. Chem., 2017, 56, 4745-4750.

22 C. Römelt, S. Ye, E. Bill, T. Weyhermüller, M. van Gastel and F. Neese, Inorg. Chem., 2018, 57, 2141-2148.

23 A. J. Morris, G. J. Meyer and E. Fujita, Acc. Chem. Res., 2009, 42, 1983-1994.

24 J. Schneider, H. Jia, J. T. Muckerman and E. Fujita, Chem. Soc. Rev., 2012, 41, 2036-2051. 
25 B. Mondal, A. Rana, P. Sen and A. Dey, J. Am. Chem. Soc., 2015, 137, 11214-11217.

26 C. Costentin, S. Drouet, G. Passard, M. Robert and J.-M. Savéant, J. Am. Chem. Soc., 2013, 135, 9023-9031.

27 M. Hammouche, D. Lexa, M. Momenteau and J. M. Saveant, J. Am. Chem. Soc., 1991, 113, 8455-8466.

28 I. Bhugun, D. Lexa and J.-M. Saveant, J. Am. Chem. Soc., 1994, 116, 5015-5016.

29 I. Bhugun, D. Lexa and J.-M. Savéant, J. Am. Chem. Soc., 1996, 118, 1769-1776.

30 C. Costentin, M. Robert and J.-M. Savéant, Acc. Chem. Res., 2015, 48, 2996-3006.

31 C. Costentin, S. Drouet, M. Robert and J.-M. Savéant, Science, 2012, 338, 90-94.

32 C. Costentin, G. Passard, M. Robert and J.-M. Savéant, Proc. Natl. Acad. Sci. USA, 2014, 111, 14990-14994.

33 I. Azcarate, C. Costentin, M. Robert and J.-M. Savéant, J. Phys. Chem. C, 2016, 120, 28951-28960.

34 I. Azcarate, C. Costentin, M. Robert and J.-M. Savéant, J. Am. Chem. Soc., 2016, 138, 16639-16644.

35 P. Gotico, B. Boitrel, R. Guillot, M. Sircoglou, A. Quaranta, Z. Halime, W. Leibl and A. Aukauloo, Angew. Chem. Int. Ed, 2019, 58 4504-4509.

36 A. Khadhraoui, P. Gotico, B. Boitrel, W. Leibl, Z. Halime and A. Aukauloo, Chem. Commun., 2018, 54, 11630-11633.

37 R. B. Ambre, Q. Daniel, T. Fan, H. Chen, B. Zhang, L. Wang, M. S. G. Ahlquist, L. Duan and L. Sun, Chem. Commun., 2016, 52, 14478-14481.

38 J. A. Bassham, A. A. Benson and M. Calvin, J. Biol. Chem., 1950, 185, 781-787.

39 G. Fuchs, Annu. Rev. Microbiol., 2011, 65, 631-658.

40 M. Can, F. A. Armstrong and S. W. Ragsdale, Chem. Rev., 2014, 114, 4149-4174.

41 H. Dobbek, V. Svetlitchnyi, L. Gremer, R. Huber and O. Meyer, Science, 2001, 293, 1281-1285.

42 J.-H. Jeoung and H. Dobbek, Science, 2007, 318, 1461.

43 J. Fesseler, J.-H. Jeoung and H. Dobbek, Angew. Chem. Int. Ed. 2015, 54, 8560-8564.

44 T. Reda, C. M. Plugge, N. J. Abram and J. Hirst, Proc. Natl. Acad. Sci. U.S.A, 2008, 105, 10654-10658.

45 H. Dobbek, Coord. Chem. Rev., 2011, 255, 1104-1116.

46 Y. Matsubara, ACS Energy Lett., 2019, 1999-2004.

47 J. M. Le and K. L. Bren, ACS Energy Lett., 2019, 2168-2180.

48 A. W. Nichols and C. W. Machan, Front. Chem., 2019, 7, 397.

49 S. Sinha and J. J. Warren, Inorg. Chem., 2018, 57, 12650-12656.

50 C. G. Margarit, C. Schnedermann, N. G. Asimow and D. G. Nocera, Organometallics, 2019, 38, 1219-1223.

51 A. J. Libbey and J. T. Stock, Anal. Chem., 1970, 42, 526-529.

52 G. Liu, Y.-J. Fan and J.-L. Zhang, J. Porphyrins Phthalocyanines, 2019, 1-8.

53 E. M. Nichols, J. S. Derrick, S. K. Nistanaki, P. T. Smith and C. J. Chang, Chem. Sci., 2018, 9, 2952-2960.

54 P. Sen, B. Mondal, D. Saha, A. Rana and A. Dey, Dalton Trans., 2019, 48, 5965-5977.

55 C. Costentin, M. Robert, J.-M. Savéant and A. Tatin, Proc. Natl. Acad. Sci. USA, 2015, 112, 6882-6886.

56 H. Rao, L. C. Schmidt, J. Bonin and M. Robert, Nature, 2017, 548, 74-77.

57 H. Rao, J. Bonin and M. Robert, J. Phys. Chem. C, 2018, 122, 13834-13839.

58 H. Rao, C.-H. Lim, J. Bonin, G. M. Miyake and M. Robert, J. Am. Chem. Soc., 2018, 140, 17830-17834.
59 E. A. Mohamed, Z. N. Zahran and Y. Naruta, Chem. Commun., 2015, 51, 16900-16903.

60 Z. N. Zahran, E. A. Mohamed and Y. Naruta, Sci. Rep., 2016, 6, 24533.

61 D. Behar, T. Dhanasekaran, P. Neta, C. M. Hosten, D. Ejeh, P.

Hambright and E. Fujita, J. Phys. Chem. A, 1998, 102, 2870-2877.

62 O. Enoki, T. Imaoka and K. Yamamoto, Macromol. Symp., 2003, 204, 151-158.

63 J. D. B. Koenig, J. Willkomm, R. Roesler, W. E. Piers and G. C. Welch, ACS Appl. Energy Mater., 2019, 2, 4022-4026.

64 B. Mondal, P. Sen, A. Rana, D. Saha, P. Das and A. Dey, ACS Catal., 2019, 9, 3895-3899.

65 Z. Chen, J. J. Concepcion, J. W. Jurss and T. J. Meyer, J. Am. Chem. Soc., 2009, 131, 15580-15581.

66 C. M. Lieber and N. S. Lewis, J. Am. Chem. Soc., 1984, 106, 5033-5034.

67 T. Yoshida, K. Tsutsumida, S. Teratani, K. Yasufuku and M. Kaneko, J. Chem. Soc., Chem. Commun., 1993, 631-633.

68 A. Tatin, C. Comminges, B. Kokoh, C. Costentin, M. Robert and J.-M. Savéant, Proc. Natl. Acad. Sci. USA, 2016, 113, 5526-5529.

69 T. Atoguchi, A. Aramata, A. Kazusaka and M. Enyo, J. Chem. Soc., Chem. Commun., 1991, 156-157.

70 N. Sonoyama, M. Kirii and T. Sakata, Electrochem. Commun., 1999, 1, 213-216.

71 J. Shen, R. Kortlever, R. Kas, Y. Y. Birdja, O. Diaz-Morales, Y. Kwon, I. Ledezma-Yanez, K. J. P. Schouten, G. Mul and M. T. M. Koper, Nat. Commun., 2015, 6, 8177.

72 Z. Weng, J. Jiang, Y. Wu, Z. Wu, X. Guo, K. L. Materna, W. Liu, V. S. Batista, G. W. Brudvig and H. Wang, J. Am. Chem. Soc., 2016, 138, 8076-8079.

73 Y. Wu, J. Jiang, Z. Weng, M. Wang, D. L. J. Broere, Y. Zhong, G. W. Brudvig, Z. Feng and H. Wang, ACS Cent. Sci., 2017, 3, 847852.

74 D. Quezada, J. Honores, M. García, F. Armijo and M. Isaacs, New J. Chem., 2014, 38, 3606-3612.

75 D. Quezada, J. Honores, M. J. Aguirre and M. Isaacs, J. Coord. Chem., 2014, 67, 4090-4100.

76 S. Aoi, K. Mase, K. Ohkubo and S. Fukuzumi, Chem. Commun., 2015, 51, 10226-10228.

77 A. Maurin and M. Robert, Chem. Commun., 2016, 52, 1208412087.

78 M. Zhu, J. Chen, L. Huang, R. Ye, J. Xu and Y.-F. Han, Angew. Chem. Int. Ed., 2019, 58, 6595-6599.

79 A. Maurin and M. Robert, J. Am. Chem. Soc., 2016, 138, 24922495.

80 X.-M. Hu, M. H. Rønne, S. U. Pedersen, T. Skrydstrup and K. Daasbjerg, Angew. Chem. Int. Ed, 2017, 56, 6468-6472.

81 P. T. Smith, B. P. Benke, Z. Cao, Y. Kim, E. M. Nichols, K. Kim and C. J. Chang, Angew. Chem. Int. Ed, 2018, 57, 9684-9688.

82 C.-H. Lim, A. M. Holder and C. B. Musgrave, J. Am. Chem. Soc., 2013, 135, 142-154.

83 S. A. Yao, R. E. Ruther, L. Zhang, R. A. Franking, R. J. Hamers and J. F. Berry, J. Am. Chem. Soc., 2012, 134, 15632-15635.

84 E. A. Mohamed, Z. N. Zahran and Y. Naruta, Chem. Mater., 2017, 29, 7140-7150.

85 B. Kumar, M. Llorente, J. Froehlich, T. Dang, A. Sathrum and C. P. Kubiak, Annu. Rev. Phys. Chem., 2012, 63, 541-569.

86 A. J. Sathrum and C. P. Kubiak, J. Phys. Chem. Lett., 2011, 2, 2372-2379.

87 I. Hod, M. D. Sampson, P. Deria, C. P. Kubiak, O. K. Farha and J.

T. Hupp, ACS Catal., 2015, 5, 6302-6309. 
88 N. Kornienko, Y. Zhao, C. S. Kley, C. Zhu, D. Kim, S. Lin, C. J. Chang, O. M. Yaghi and P. Yang, J. Am. Chem. Soc., 2015, 137, 14129-14135.

89 S. Lin, C. S. Diercks, Y.-B. Zhang, N. Kornienko, E. M. Nichols, Y. Zhao, A. R. Paris, D. Kim, P. Yang, O. M. Yaghi and C. J. Chang, Science, 2015, 349, 1208.

90 C. S. Diercks, S. Lin, N. Kornienko, E. A. Kapustin, E. M. Nichols, C. Zhu, Y. Zhao, C. J. Chang and O. M. Yaghi, J. Am. Chem. Soc., 2018, 140, 1116-1122.

91 A. R. Battersby, C. J. R. Fookes, G. W. J. Matcham and E. McDonald, Nature, 1980, 285, 17-21.

92 S. Ren, D. Joulié, D. Salvatore, K. Torbensen, M. Wang, M. Robert and C. P. Berlinguette, Science, 2019, 365, 367-369. 